Center for Applied Energy Research

and

Rentucky Transportation center

\title{
October 1992
}

Prepared for

\author{
The 0. 8. Department of Energy \\ under contract No.
}

DE-AC21-91-MC8162

\section{DISCLAIMER}

This report was prepared as an account of work sponsored by an agency of the United States Government. Neither the United States Government nor any agency thereof, nor any of their employees, makes any warranty, express or implied, or assumes any legal liability or responsibility for the accuracy, completeness, or usefulness of any information, apparatus, product, or

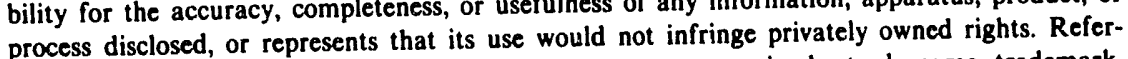
ence herein to any specific commercial product, process, or service by trade name, trademark, manufacturer, or otherwise does not necessarily constitute or imply its endorsement, recommendation, or favoring by the United States Government or any agency thereof. The views and opinions of authors expressed herein do not necessarily state or reflect those of the United States Government or any agency thereof. 
INDEX

$\begin{array}{ll}\text { SUMMARY } & 1\end{array}$

$\begin{array}{lc}\text { WORK PERFORMED } & 8\end{array}$

Subtask 2.1 - SAMPLE COLLECTION 8

Subtask 2.2 - CHEMICAL AND MINERALOGICAL 9 CHARACTERIZATION OF THE WASTE COOLSIDE PLANT WASTE 10

Ultimate and Proximate Analysis 10

Major and Minor Element Analysis 10

X-Ray Diffraction 20

Scanning Electron Microscopy 20

PILOT PLANT COOLSIDE WASTE SAMPLES 21

Subtask 2.3 - GEOTECHNICAL CHARACTERIZATION OF THE WASTE 25

INDEX PROPERTIES AND CLASSIFICATION 25

STRUCTURAL PROPERTIES

Compaction 26

Swelling Properties $\quad 32$

Shear strength 38

Bearing strength 40

Triaxial strength 41

Permeability $\quad 44$

Potential Applications 46

Task 3. FIELD LEACHING STUDIES 47

Task 4. LABORATORY LEACHING STUDIES 48

BATCH PROCEDURES 48

Analysis Procedures 48

Ion Determination in Leachate 50

Analysis Results $\quad 50$

WASTE CHARACTERIZATION 54

Toxicity Characteristic 54

Ignitability 54

Reactivity 54

Corrosivity 54

COLUMN STUDIES 55

Pilot Plant Samples of Coolside Waste $\quad 56$

Lab Simulation of Field Lysimeters 59 


\section{SUMMLARY}

8ample collection - Soils, base sand, and conventional fly ash for loading the field lysimeter cells were selected and either obtained or in process of being delivered.

Chemical and Mineralogical Characterization of the waste - This activity is proceeding with proximate and ultimate analysis of the materials being completed. In addition the major and minor element analysis was performed by several analytical techniques. The protocol for rapid, thick-target proton induced $x$-ray emission (PIXE) and proton induced gamma emission (PIGE) spectroscopy were developed. Analysis of 97 Coolside waste samples from Run 3 and 77 samples from Run 1 showed a wide range of concentration values were observed for most of the values.

In Run 3 calcium content increased with time and titanium content decreased. Likewise, a change in sodium content occurred with average concentrations being $1.26 \pm 0.03$ wt\% during the first half of the run while it dropped to $1.18 \pm 0.03$ wt\% in the latter part of the run. Vanadium and bromine directly correlate with the calcium content indicating these elements are either introduced in the hydrated lime or their capture efficiency depends on the calcium concentration in the waste. The other elements whose concentrations increase with time are zinc, germanium, arsenic, gallium and lead but do not appear to be introduced with the lime or have capture efficiencies that are affected by the calcium content in the ash.

$X$-Ray diffraction analysis showed the material contained constituents consistent of the fly ash present in the material plus the scrubber agent added to the stream. The crystalline material consistent with fly ash type materials were quartz and mullite, a semi-crystalline aluminosilicate. The scrubber 
reagent related materials were portlandite $\left(\mathrm{Ca}(\mathrm{OH})_{2}\right)$, gypsum and halite (NaCl). SEM showed the materials were comprised of aluminum and silicon rich spheres and ellipsoids with 10-20 $\mu \mathrm{m}$ diameters. The calcium rich portion of the waste is arranged in agglomerates of $\mathrm{Ca}(\mathrm{OH})_{2}$ that range in size from 2-50 $\mu \mathrm{m}$ and typically contain smaller Al-si fly ash spheres. Unburned carbon was observed in the material as perforated spheres having diameters of about $50 \mu \mathrm{m}$.

Detailed elemental analysis of four pilot plant materials, including $\mathrm{X}$-Ray fluorescence and PIXE/PIGE analysis were performed. Sodium concentrations consistent with run conditions, i.e., 2 wt. $q$ in tests 1 and 2 and 0.18 wt. $\%$ in test 3 and 4 were observed. The difference in the concentration of most of the trace elements can be attributed to the lower ash content of the pilot samples. The lower scandium concentration in the coolside samples may be attributed to the higher calcium content of the pilot materials which likely enhances the strontium values.

Geotechnical Characterization of the waste - Tests were performed to characterize the physical properties of the coolside waste and to examine potential disposal schemes and uses of the material. Coolside waste is non-plastic with a specific gravity of 2.53 , which is less than that of many typical soils which range from 2.60 to 2.85 . The waste is a fine-grained material with $100 \%$ passing through a U.S. No. 10 sieve and about 94 to 96 percent passing through a No. 200 sieve. The particle-size composition of the material is consistently uniform while the silt-size fraction ranges from 75 to 85 percent. Sand-size and clay-size particles compose about 5 percent and 15 percent $(<0.005 \mathrm{~mm}-$ size), respectively, of the material matrix with about 6 percent of the material consisting of particles smaller than $2 \mu \mathrm{m}$.

The waste is classified as ML based on the Unified Soil 
Classification System (ASTM D 2487-85, 1988) which is described as a silt, or silt with sand. Under the AASHTO Classification system, the waste is classified as A-4(0). Although silts are normally susceptible to frost penetration, the coolside waste may not behave in a similar manrier (except during initial placement) because the material tends to hydrate and stiffen as it ages.

The relationships between both dry density and optimum moisture content and compactive effort were performed at modified compaction (ASTM D 1557-78), standard compaction (ASTM D 698-78), and low energy compaction. As compactive energy increases, the maximum dry density increases and optimum moisture decreases. Dry density of the Coolside material in a loose, dry state obtained from static compactive effort is only about 36 percent higher than the loose-state density. The maximum dry density of the coolside material obtained from standard compaction is about 1.9 times the dry density of the material in a loose state. However, the maximum dry density at modified compaction is only about 1.12 times the maximum dry density at standard compaction. Hence, a four fold increase in compactive energy above standard compactive energy increases the dry density only 12 percent suggesting that obtaining maximum dry density from standard compaction would probably be uneconomical. optimum moisture content at standard compaction is about 36.5 percent. Compacting the waste when the water content is higher than the optimum moisture content could pose a problem since it may liquefy because of its large silt content.

Magnitude and rate of swelling of the waste are both important factors. If the rate of swelling is large, little damage may occur if the total magnitude of swelling is small. Likewise, if the total magnitude of swelling is large, no damage may occur if the swelling occurs rapidly. Results showed that swelling of non-aged coolside compacted specimens are larger than those of two typical clays though the magnitudes are less than a compacted 
mixture of a soil sample.

Primary swell of the Coolside compacted specimens are much greater than those of the compacted typical soils with coefficients, $c_{p s}$, of the specimens where no aging was allowed were 4 to 300 times larger than the values of the typical soils. primary swell occurred rapidly of non-aged specimens which were not allowed to age prior to soaking.

Aging of compacted specimens changes the swelling characteristics of the material. Swelling magnitudes of specimens aged for 7 days before soaking ranged from 1 to 5 percent indicating the aging process decreases swelling significantly. These magnitudes are less than the swelling of two typical soils. The combined effects of aging and surcharging caused large decreases in the magnitudes of swell. In all cases, the coefficients of secondary swell of the compacted specimens of coolside waste were low and they ranged from 0.0 to 0.009 . These values are similar to those observed for the two typical soils.

Shear strength is important at different times of aging since construction equipment must operate on the material soon after application. The initial bearing strength was determined by performing the California Bearing Ratio tests on unsoaked, compacted specimens remolded at different moisture contents and penetrated immediately after compaction. The target CBR strength of a bearing media must be greater than about 6 to be feasible for road type applications. As the molding moisture content increases at a constant molding dry density, strength decreases. At four percent above the optimum moisture content (40.8), the CBR value is 3.7 percent. For Coolside material it appears the placement moisture content should not be greater than 2 percent above optimum moisture content. However, to limit tire sinkage, the placement water content should not exceed optimum 
moisture content. CBR tests on specimens soaked for 4 days compacted at 95 percent of maximum dry densities obtained from modified, standard, and low-energy compaction tests indicated these materials gained enormous strength during the soaking period.

Unconfined compression tests performed on remolded specimens remolded to 95 percent of standard maximum dry density and optimum moisture content and aged in sealed containers at room temperature $\left(\approx 21^{\circ} \mathrm{C}\right)$ showed unconfined strength increases from a value of about $252 \mathrm{kPa}$ at a seven-day aging period to about 8984 $\mathrm{kPa}$ for an 188-day aging period, that is, the strength gain at the end of about 6 months is some 35 times the seven-day strength.

Permeability tests performed on specimens remolded to different. densities and different aging times indicate that aging does not significantly affect the permeability coefficient which decreases as the void ratio decreases and the dry density increases. The coefficient of permeability for the coolside waste ranges from about $4 \times 10^{-5} \mathrm{~cm} / \mathrm{sec}$ to $3 \times 10^{-6} \mathrm{~cm} / \mathrm{sec}$. which may be described as low to very low. However, the material in a compacted state is not impermeable since the coefficient of permeability is not smaller than $10^{-7} \mathrm{~cm} / \mathrm{sec}$.

Field Lysimeters studies - Filling of the field lysimeters has begun. A mixing pad was built and completed and water storage capability was added for moistening samples during the filling process. All materials, equipment and supplies for filling the field lysimeters. including 30,000 lbs of ottawa sand to serve as the base layer in the lysimeters was ordered and transported to the site as needed. Analysis of samples of the sand and the soils indicated these materials would no complicate interpretation of the results. of particular concern was the 
possible presence of adsorbed or occluded soluble species that would leach out during the early stages of the leaching thereby possibly generating significant impurities in the initial

leachate samples.

Laboratory Leaching studies - Four extractions on Coolside material were performed that included two ASTM procedures and two standard EPA extractions, i.e., EPTOX and TCLP. There were no major surprises resulting from these extraction procedures. The concentrations of the majority of the trace metals were below the instrument's detection limits. The TCLP shows higher yields than the EPTOX because of the lower pir buffer and a more rigorous agitation method. The heavy metal concentrations in the coolside material were less than those specified under TCLP. The material is a nonreactive inorganic solid and is completely noncombustible such that the Ignitability and Reactivity characteristic does not apply. Although the material exhibits a pH greater than 12.5 since it is a solid material the corrosivity characteristic does not apply.

Columns leaching was also performed in the laboratory to investigate the leaching characteristics that will occur in the field. The $\mathrm{pH}$ of the column leachates were strongly alkaline with leachate $\mathrm{pH}$ values of 12.5 . The major constituents of the leachates were $\mathrm{SO}_{4}, \mathrm{Cl}, \mathrm{Na}$, and $\mathrm{Ca}$. These cations and anions leached rapidly but reached equilibrium within 4 weeks.

Laboratory lysimeter tests on columns packed with coolside waste are being run in addition to the 4 pilot plant run samples provided by consol. Loadings were made at static, proctor and low packing densities of which 13 are being run under conditions simulating annual weekly rainfall taken at a near farmers site while the remaining 12 columns will be kept saturated and be leached at a rate of $70 \mathrm{ml} /$ week. The effect of an enriched $\mathrm{CO}_{2}$ 
partial pressure over the column on the column performance and the composition of the leachate will be determined. Analysis of the leachate will follow protocol established in the program. Total material balances and metal and ion balances around the columns will be developed. 


\section{WORR PERFORMED}

\section{SUBTASK 2.1 - SAMPLE COLLECTION}

ottawa sand was selected to provide the base layer in the laboratory and field lysimeter columns. Local common colluvial soil typical of the Cumberland plateau found in northeast Kentucky and southeast ohio has been chosen to cover the individual cells. Soils that were to have been provided by waste Management would essentially seal the cells to water percolation because of its extremely low permeability. The consol coolside pilot plant samples were obtained and are currently being evaluated. Likewise, a sample of fly ash from TransAsh in cincinnati, Ohio is being obtained for loading into the fourth cell.

SUBTAGK 2.? - CHEMICAL AND MINERALOGICAL CHARACTERIZATION OF THE พASTE

\section{COOLSIDE PLANT WASTE}

Oltimate and Proximate Analysis - Ultimate and proximate analysis of the solid waste material were performed in accordance with the American Society for Testing and Materials, procedures Dj172 and D3176 and are shown in Table 1. The proximate analysis includes moisture, ash, volatile and fixed carbon reported on an as received basis. The ultimate analysis includes carbon, hydrogen, nitrogen, sulfur, oxygen, and ash and are reported on a dry basis.

Major and Minor Element Analysis - The major elements were determined using a variety of analytical techniques including PIXE and PIGE, $x$-ray fluorescence, ICP, and AA (FIAS). The trace elements (Ag, As, B, Ba, Be, Cl, Co, Cd, Cr, Cu, F, Hg, Mn, Ni, $\mathrm{Pb}, \mathrm{Se}, \mathrm{V}$, and $\mathrm{Zn}$ ) were determined using the same techniques used for the major elements with the addition of an Ion chromatograph. 
Table 1.- Proximate And oltimate Analysis of coolside samples.

\begin{tabular}{cccccc} 
8ample & Moisture & Volatile Matter & Ash & \multicolumn{2}{c}{ Fixed Carbon } \\
300 series & $.84 \%$ & $11.99 \%$ & $85.48 \%$ & $1.68 \%$ \\
1000 series & $.68 \%$ & $11.20 \%$ & $86.50 \%$ & $1.60 \%$ \\
8ample & Carbon & Hydrogen & Nitrogen & 8ulfur & Oxygen \\
300 series & $6.66 \%$ & $.39 \%$ & $.58 \%$ & $2.02 \%$ & 4.87 \\
1000 series & $5.42 \%$ & $.43 \%$ & $.58 \%$ & $1.86 \%$ & 5.21
\end{tabular}

The samples were prepared for analysis by converting the insoluble material to soluble forms using digestion techniques which included heating in the presence of boiling acid solutions, fusion with lithium tetraborate, and dissolution using a CEM microwave digestion oven.

Table 2 contains analytical data obtained from a homogenous mixture of Coolside material of the 300 series. The trace elements were performed using a spectrametric 111 ICP spectrometer equipped with a CETAC 5100 Ultrasonic Nebulizer. The major elements were performed using the spectrometric 111 DCP. In this method 0.1 gram of coolside sample was placed into a teflon PFA vessel with a pressure relief valve. Three milliliters each of nitric, hydrochloric and hydrofluoric acids were added to the material and the samples heated in the microwave for 20 minutes with, pressures less than 100 psi after which $50 \mathrm{mls}$ of saturated boric acid was added and the samples reheated in the microwave and then analyzed. A comparative chemical analysis using $1633 \mathrm{~A}$ as the quality control sample to assure the accuracy of the coolside results was performed. The results were obtained by the combination of ICP-DCP and X-ray fluorescence analysis.

An analytical protocol for the rapid, thick-target PIXE/PIGE 
analysis of the coolside waste material has been developed. The concentrations of 5 major elements ( $\mathrm{Al}, \mathrm{Ca}, \mathrm{Fe}, \mathrm{K}$, and $\mathrm{Na}$ ) and 22 trace elements are determined in a single, 10 minute irradiation.

\section{Table 2.- Major And Trace Elemental Analysis Standard sample 1633A}

\begin{tabular}{|c|c|c|c|c|}
\hline Element & Actual & Observed & Actual/observed & Coolside \\
\hline $\mathrm{Ag}$ & - & 13 & - & 12.3 \\
\hline Al & 14.38 & 15.08 & 958 & $9.68 \%$ \\
\hline $\mathbf{B a}$ & 0.158 & 0.148 & $107 \%$ & $334 \mathrm{ug} / \mathrm{g}$ \\
\hline $\mathbf{C a}$ & 1.118 & $1.12 \%$ & 998 & $10.0 \%$ \\
\hline Fe & $9.40 \%$ & $9.66 \%$ & 978 & $7.10 \%$ \\
\hline $\mathbf{K}$ & 1.888 & 1.728 & 1098 & 1.668 \\
\hline $\mathbf{M g}$ & $0.46 \%$ & $0.46 \%$ & $100 \%$ & 0.628 \\
\hline Na & $0.17 \%$ & $0.18 z$ & $94 \%$ & $1.25 \%$ \\
\hline $\mathbf{P}$ & - & $0.12 \%$ & - & 0.098 \\
\hline $\mathbf{8 i}$ & 22.88 & 22.38 & 1028 & $15.9 \%$ \\
\hline $\mathbf{T i}$ & $0.80 \%$ & 0.838 & $96 \%$ & $0.45 \%$ \\
\hline Be & $12 \mathrm{ug} / \mathrm{g}$ & $12 \mathrm{ug} / \mathrm{g}$ & 1008 & $15 \mathrm{ug} / \mathrm{g}$ \\
\hline Co & 46 & 43 & $107 \%$ & 42 \\
\hline $\mathrm{Cu}$ & 118 & 114 & $104 \%$ & 70 \\
\hline Mn & 178 & 179 & $99 \%$ & 132 \\
\hline Mo & 29 & 30 & $97 \%$ & 33 \\
\hline $\mathbf{N i}$ & 127 & 128 & 998 & 159 \\
\hline $\mathbf{P b}$ & 72 & 72 & $100 \frac{8}{6}$ & 27 \\
\hline $\mathbf{z n}$ & 220 & 214 & $103 \%$ & 216 \\
\hline
\end{tabular}

In this procedure the fly ash is first oven dried for 24 hours at $105^{\circ} \mathrm{C}$. Samples are then prepared by mixing $100 \mathrm{mg}$ of the dried ash with $200 \mathrm{mg}$ of high purity graphite (Johnson Matthey, Ultra F) in a methyl methacrylate mixer-mill vial and pressing c.a. 100 $\mathrm{mg}$ of this mixture into a pellet at $90 \mathrm{MPa}$ in a $13-\mathrm{mm}$ diam. stainless steel die. The samples are then irradiated for $10 \mathrm{~min}$. with an external $2.5 \mathrm{MeV}$ proton beam in 1 atm. of He. The PIXE 
analyses are standardized using a series of "elemental" samples prepared by spiking high purity graphite with single and multielement NIST SRM spectrometric solutions. Results of the PIXE analysis of three pellets prepared from the fly ash reference material NIST $1633 \mathrm{a}$ are given in Table 3 to demonstrate the accuracy and relative precision of the measurements. Note that while the simultaneous PIGE analysis also provides concentration information for the light elements $\mathrm{Li}, \mathrm{F}, \mathrm{Na}$ and $\mathrm{Al}$, no values are given for these elements as these measurements are performed using the comparative method with NIST $1633 a$ as the reference material.

The results of the PIXE/PIGE analysis of 97 Coolside waste samples from Run 3 (Barrels 305 througn 401) and 77 samples from Run 1 are given in Table 4. The wide range of concentration values observed for most of the elenents indicates that, as one would expect, the coolside waste is a very heterogenous material. For this reason, it is important to investigate the composition of a large number of samples in order to obtain a reasonable estimate of the elemental composition of the composited waste in the field lysimeters.

The concentration of the major elements determined by PIXE/PIGE in samples from Run 3 are plotted against Barrel number in Figure 1. It is clear that the calcium content of the coolside waste increased with time during Run 3 and that the titanium content of the waste decreased with time during Run 3. It also appears that there was a sharp change in the sodium content during the course of this run. The average sodium concentration of samples 305 to 347 is $1.26 \pm 0.03$, at the $99 \%$ confidence level, while the average sodium concentration of samples 348 to 401 is $1.18 \pm$ 0.02 , at the $99 \%$ confidence level. We are currently accumulating the information needed to correlate these variations with the operating parameters of the plant during Run 3. 
Table 3. Instrumental PIXE analysis of NI8T IlY ash standard $1633 a^{\circ}$

Element PIXE (n=3) RBD (8) Certified value Obs/actual

$\begin{array}{ccccc}\mathrm{K} & 1.7 \pm 0.1 & 5.9 & 1.88 \pm 0.06 & 0.93 \\ \mathrm{Ca} & 1.08 \pm 0.04 & 3.5 & 1.11 \pm 0.01 & 0.98 \\ \mathrm{Ti} & 0.78 \pm 0.02 & 3.3 & {[0.82 \pm 0.04]^{\mathrm{b}}} & 0.97 \\ \mathrm{~V} & 279 \pm 19 & 6.8 & 297 \pm 6 & 0.94 \\ \mathrm{Cr} & 186 \pm 7 & 3.6 & 196 \pm 6 & 0.95 \\ \mathrm{Mn} & 166 \pm 9 & 5.3 & 179 \pm 8 & 0.93 \\ \mathrm{Fe} & 9.1 \pm 0.3 & 3.1 & 9.4 \pm 0.1 & 0.97 \\ \mathrm{Ni} & 135 \pm 16 & 12 & 127 \pm 4 & 1.06 \\ \mathrm{Cu} & 118 \pm 6 & 5.2 & 118 \pm 3 & 1.00 \\ \mathrm{Zn} & 216 \pm 7 & 3.4 & 220 \pm 10 & 0.98 \\ \mathrm{Ga} & 60 \pm 3 & 5.8 & {[56 \pm 3]^{\mathrm{b}}} & 1.03 \\ \mathrm{Ge} & 30 \pm 6 & 18 & {[33.9 \pm 0.2]^{\mathrm{b}}} & 0.88 \\ \mathrm{As} & 141 \pm 4 & 3.0 & 145 \pm 15 & 0.98 \\ \mathrm{Se} & 12 \pm 2 & 18 & 10.3 \pm 0.6 & 1.17 \\ \mathrm{Rb} & 139 \pm 8 & 5.9 & 131 \pm 2 & 1.06 \\ \mathrm{Sr} & 780 \pm 30 & 4.0 & 830 \pm 30 & 0.95 \\ \mathrm{Y} & 74 \pm 9 & 12 & {[82 \pm 6]^{\mathrm{b}}} & 0.90 \\ \mathrm{Zr} & 231 \pm 15 & 6.4 & {[330 \pm 80]^{\mathrm{b}}} & 0.70 \\ \mathrm{Nb} & 24 \pm 4 & 15 & {[28]^{\mathrm{b}}} & 0.86 \\ \mathrm{Mo} & 26 \pm 9 & 35 & {[29]^{\mathrm{b}}} & 0.90 \\ \mathrm{Ba} & 1260 \pm 100 & 7.9 & {[1500]^{\mathrm{b}}} & 0.84 \\ \mathrm{~Pb} & 94 \pm 30 & 28 & 72.4 \pm 0.4 & 1.44\end{array}$

a. Concentration in weight percent

b. Non-certified, compilation value ${ }^{1}$

1 E.S. Gladney et al., Standard Reference Materials Compilation of Elemental Concentration, Data for NBS Clinical, Biological, Geological and Environmental standard Reference Materials, NBS Spec. Publ. 260-111 (1987). 
Table 4. Elemental composition of coolside waste samples from Run 3 and Run 1 by PIXE/PIGE analysis.

Element

Run $3(n=97)$

Avg. Max Min Avg. Max Min

Run $1(n=77)$

\begin{tabular}{|c|c|c|c|c|c|c|}
\hline Al $(\xi)$ & $9.5 \pm 0.8$ & 13.2 & 7.7 & $\star \star$ & & \\
\hline $\mathrm{Ca}(q)$ & $8.6 \pm 1.4$ & 11.3 & 5.6 & $10.6 \pm 1.7$ & 13.8 & 7.0 \\
\hline $\mathrm{Fe}(q)$ & $5.9 \pm 0.5$ & 7.3 & 4.9 & $6.6 \pm 0.6$ & 8.2 & 4.2 \\
\hline$K(z)$ & $1.26 \pm 0.07$ & 1.3 & 1.0 & $1.4 \pm 0.1$ & 1.7 & 1.2 \\
\hline $\mathrm{Na}(q)$ & $1.22 \pm 0.08$ & 1.42 & 1.00 & $\star \star$ & & \\
\hline As & $227 \pm 16$ & 277 & 191 & $217 \pm 44$ & 317 & 135 \\
\hline $\mathbf{B a}$ & ee & & & $583 \pm 182$ & 950 & 246 \\
\hline $\mathrm{Br}$ & $124 \pm 11$ & 150 & 96 & $104 \pm 85$ & 141 & 53 \\
\hline $\mathrm{cu}$ & $82 \pm 8$ & 98 & 63 & $78 \pm 6$ & 92 & 53 \\
\hline $\mathbf{F}$ & $415 \pm 60$ & 654 & 286 & ** & & \\
\hline $\mathbf{G a}$ & $39 \pm 5$ & 50 & 29 & $35 \pm 6$ & 46 & 19 \\
\hline Ge & $49 \pm 4$ & 61 & 3 & $48 \pm 10$ & 69 & 24 \\
\hline Li & $81 \pm 12$ & 129 & 59 & ** & & \\
\hline Mn & $100 \pm 11$ & 12.9 & 76 & $118 \pm 13$ & 204 & 81 \\
\hline Mo & $29 \pm 7$ & 46 & 10 & $29 \pm 6$ & 50 & 14 \\
\hline $\mathrm{Ni}$ & $78 \pm 11$ & 167 & 61 & $70 \pm 8$ & 84 & 41 \\
\hline $\mathrm{Pb}$ & $74 \pm 11$ & 104 & 46 & $134 \pm 29$ & 196 & 66 \\
\hline $\mathrm{Rb}$ & $101 \pm 10$ & 127 & 80 & $98 \pm 10$ & 118 & 59 \\
\hline $\mathrm{Sc}$ & $197 \pm 49$ & 340 & 57 & & & \\
\hline Se & $15 \pm 4$ & 24 & 6 & $11 \pm 4$ & 19 & 2 \\
\hline Sr & $322 \pm 33$ & 386 & 121 & $310 \pm 27$ & 362 & 203 \\
\hline $\mathrm{Ti}$ & $3428 \pm 230$ & 3825 & 2881 & $4033 \pm 312$ & 4926 & 2791 \\
\hline V & $172 \pm 11$ & 197 & 143 & $187 \pm 16$ & 215 & 151 \\
\hline $\mathrm{Y}$ & $61 \pm 8$ & 75 & 42 & $63 \pm 8$ & 86 & 37 \\
\hline $\mathrm{Zn}$ & $292 \pm 25$ & 424 & 241 & $279 \pm 39$ & 360 & 191 \\
\hline $\mathrm{Zr}$ & $153 \pm 18$ & 239 & 110 & $192 \pm 24$ & 224 & 113 \\
\hline
\end{tabular}

** Data analysis to be performed ee Improved the precision of the barium measurement by measuring the $\mathrm{Ba} \mathrm{K}$-line instead of the Ba L-line. Run 3 samples will be re-analyzed for Ba. 
The trace elements whose concentrations appear to vary with time during Run 3 are plotted in Figure 2. Like titanium, the concentrations of both zinc and arsenic decline during this run. on the other hand, there is a sharp increase in the concentration of strontium near the end of the run. The average strontium concentration of samples 305 to 373 is $309 \pm 9$ (99\% confidence level) while the average strontium concentration of samples 374 to 401 is $358 \pm 8$ (998 confidence level).

The concentration of the major elements determined by PIXE/PIGE in samples from Run 1 are plotted against Barrel number in Figure 3. The most striking observation from this figure is the sharp increase in the calcium content of the waste early in Run 1 . The average calcium concentration of samples 28 to 54 is $7.9 \pm 0.3$ (99\%) while the average calcium concentration of samples 64 to 176 is $11.4 \pm 0.4$ (99z).

The trace elements whose concentrations vary with time during Run 1 are plotted in Figures 4 and 5 . It is interesting that, in contrast to demonstration Run 3, there are several trace elements whose concentrations clearly change with time during the run. The concentration versus sample (time) profiles of vanadium and bromine indicate that the concentration of these two species are directly correlated with the calcium concentration of the waste; either the majority of vanadium and bromine in the waste is introduced in the hydrated lime or the capture efficiency for these two species depends critically on the calcium concentration of the waste. These two premises will be investigated by determining the elemental composition of the hydrated lime used in the demonstration project. The other trace elements whose concentrations clearly increase with time during Run 1 are $z$ inc, germanium, arsenic, gallium, and lead. Because the concentration of these species does not abruptly increase, as in the case of vanadium and bromine, we conclude that they are not introduced into the waste with the lime or that theix capture efficiency is 
FIGURE 1
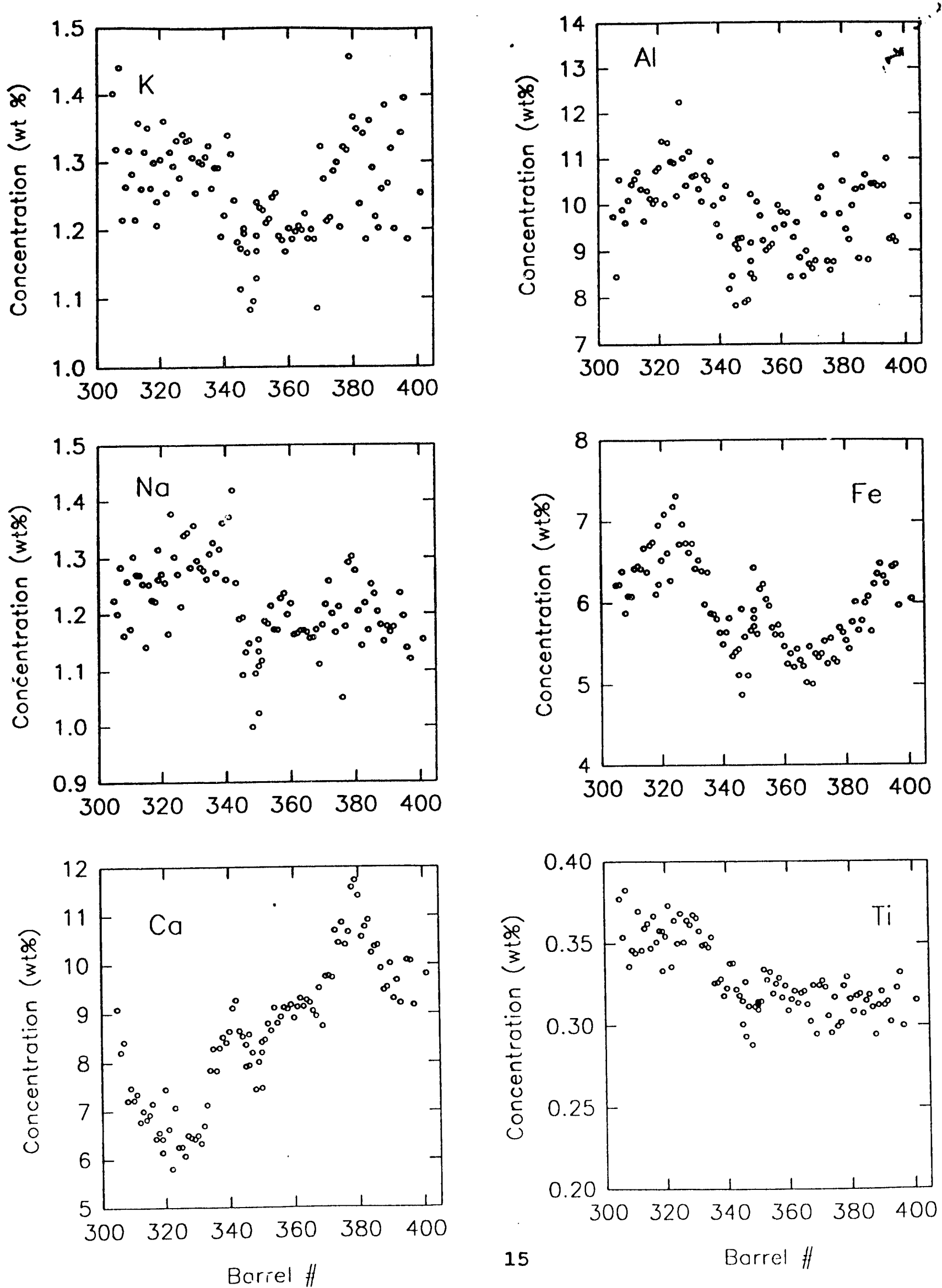
FIGURE 2
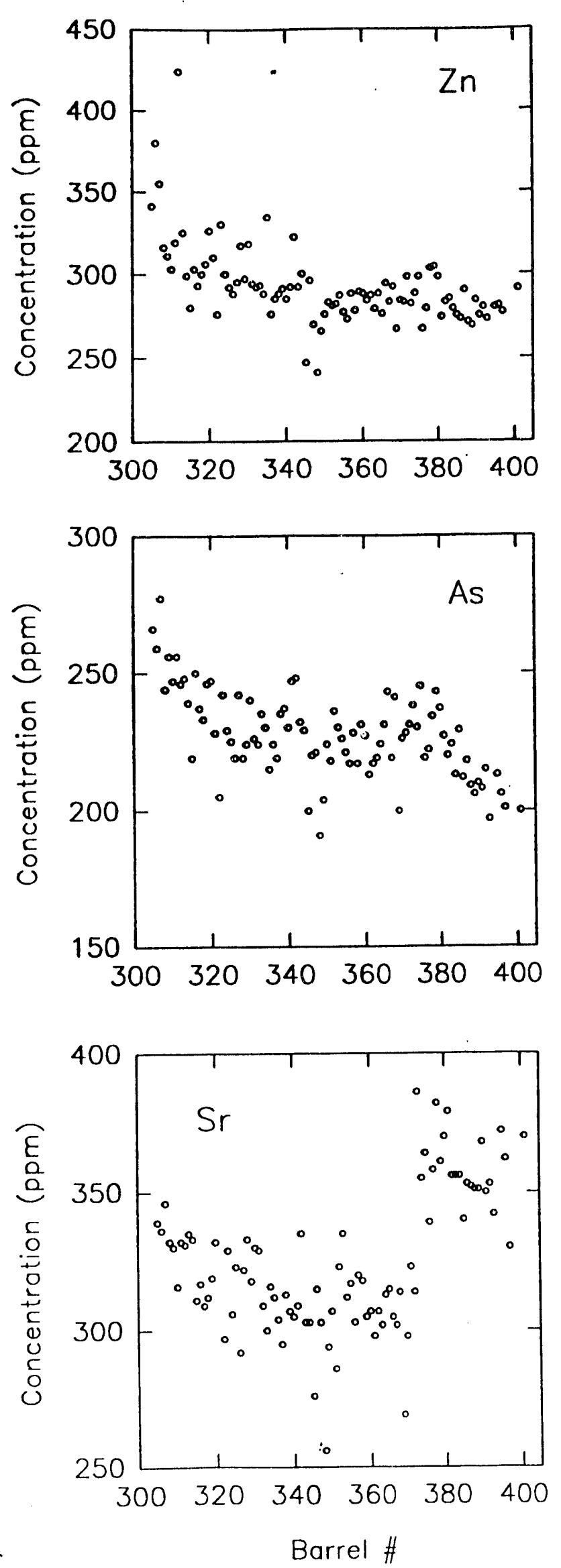
FIGURE 3

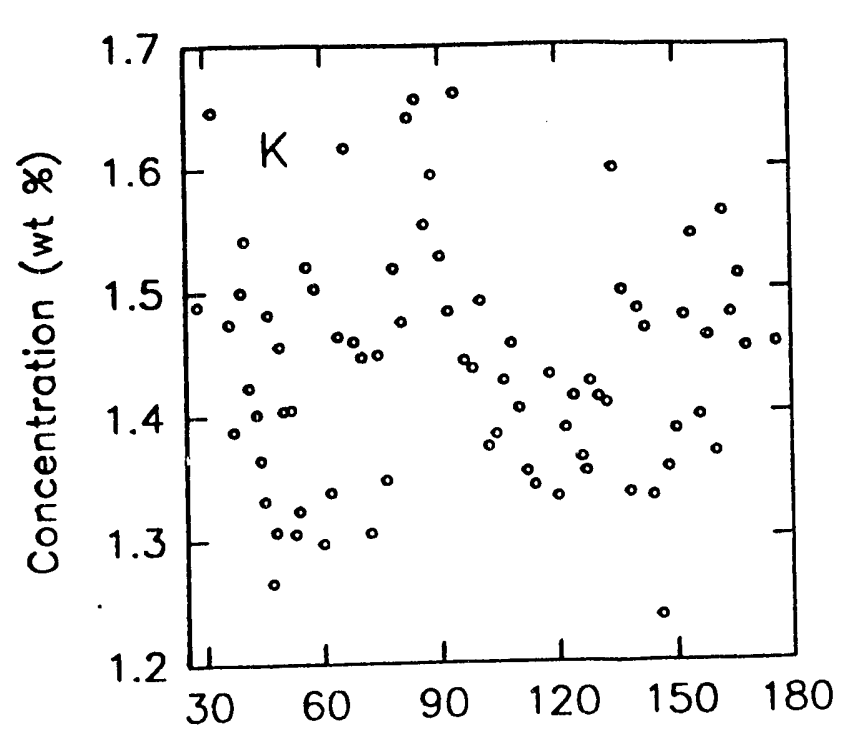

Al
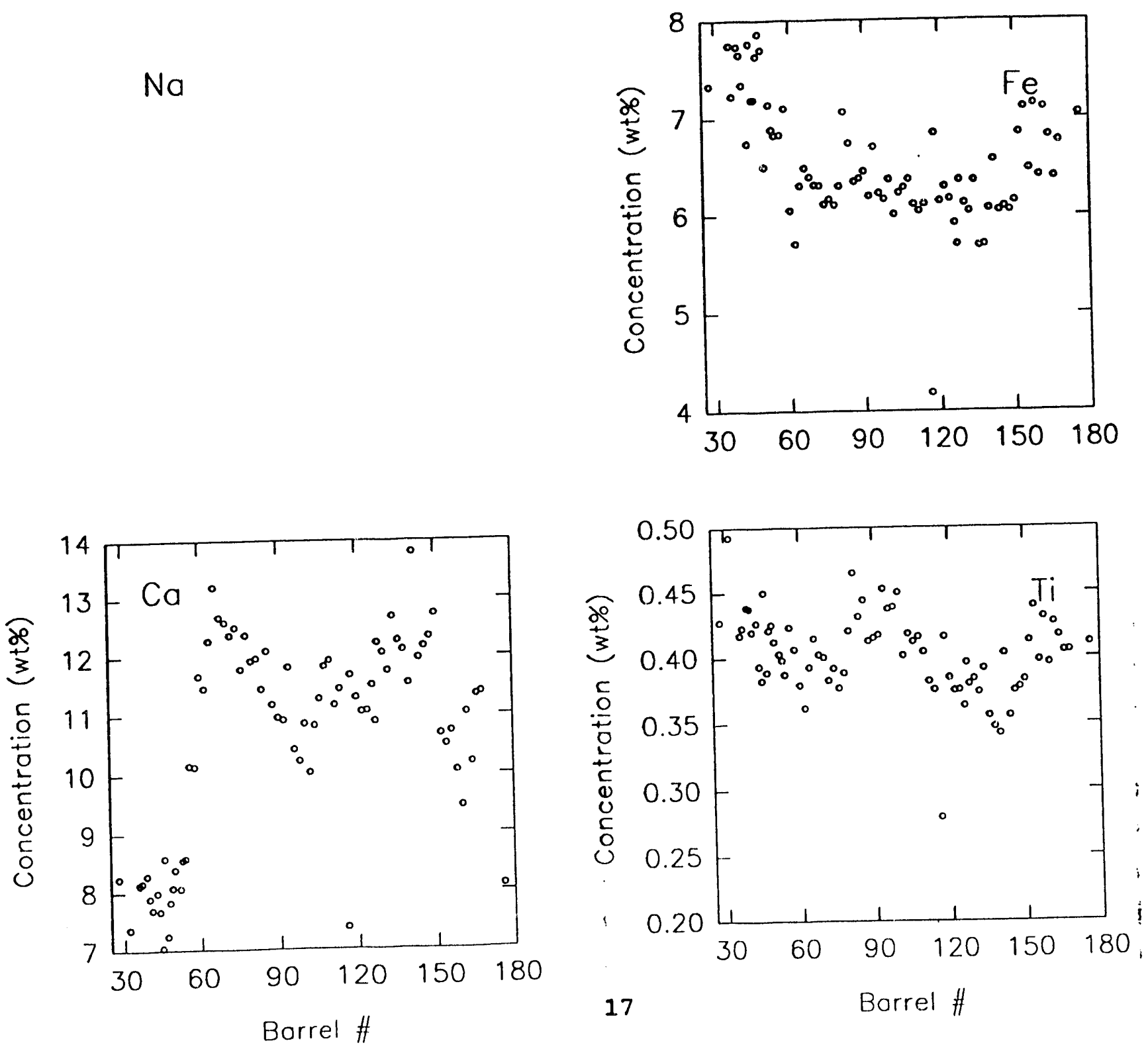
FIGURE 4
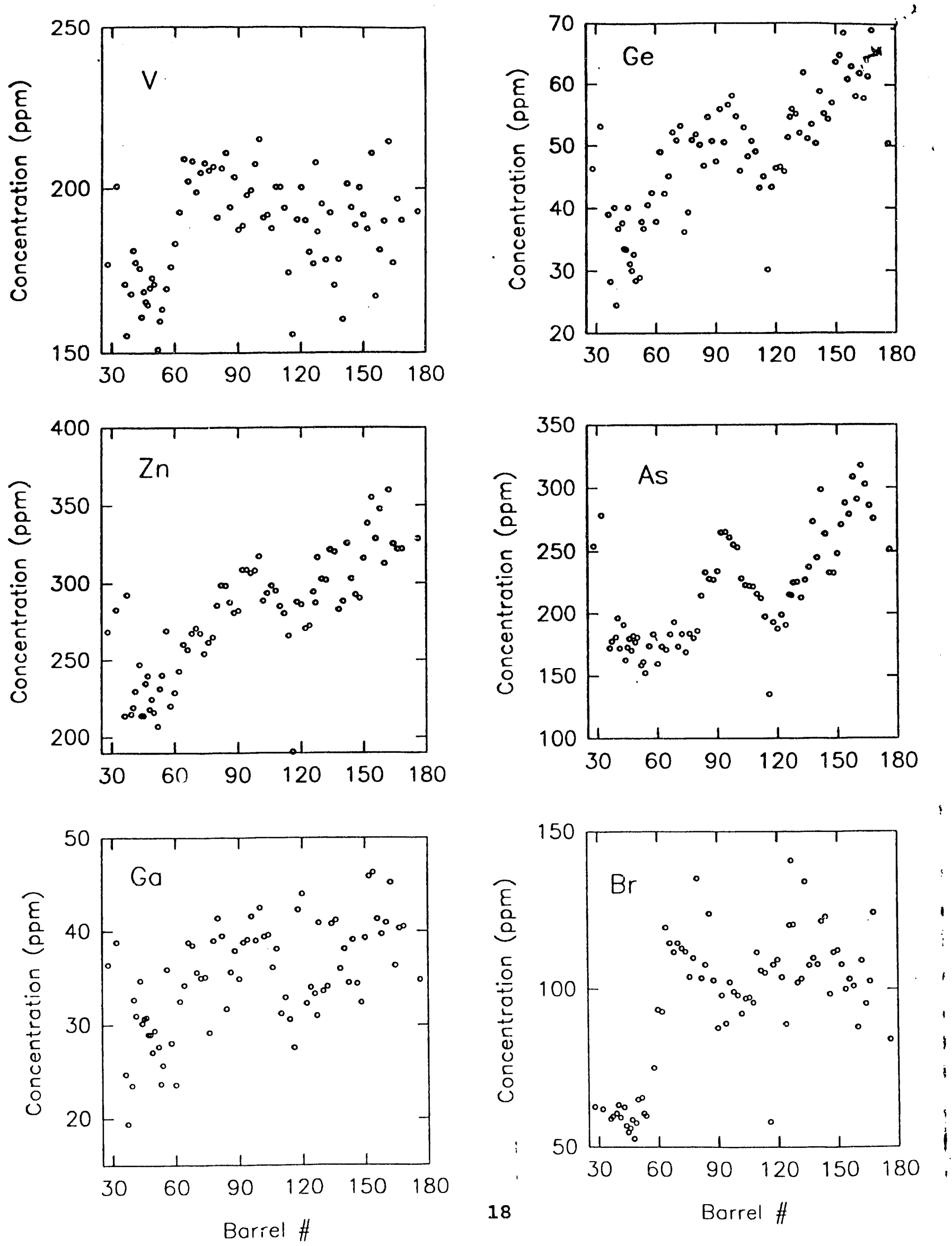
FIGURE 5
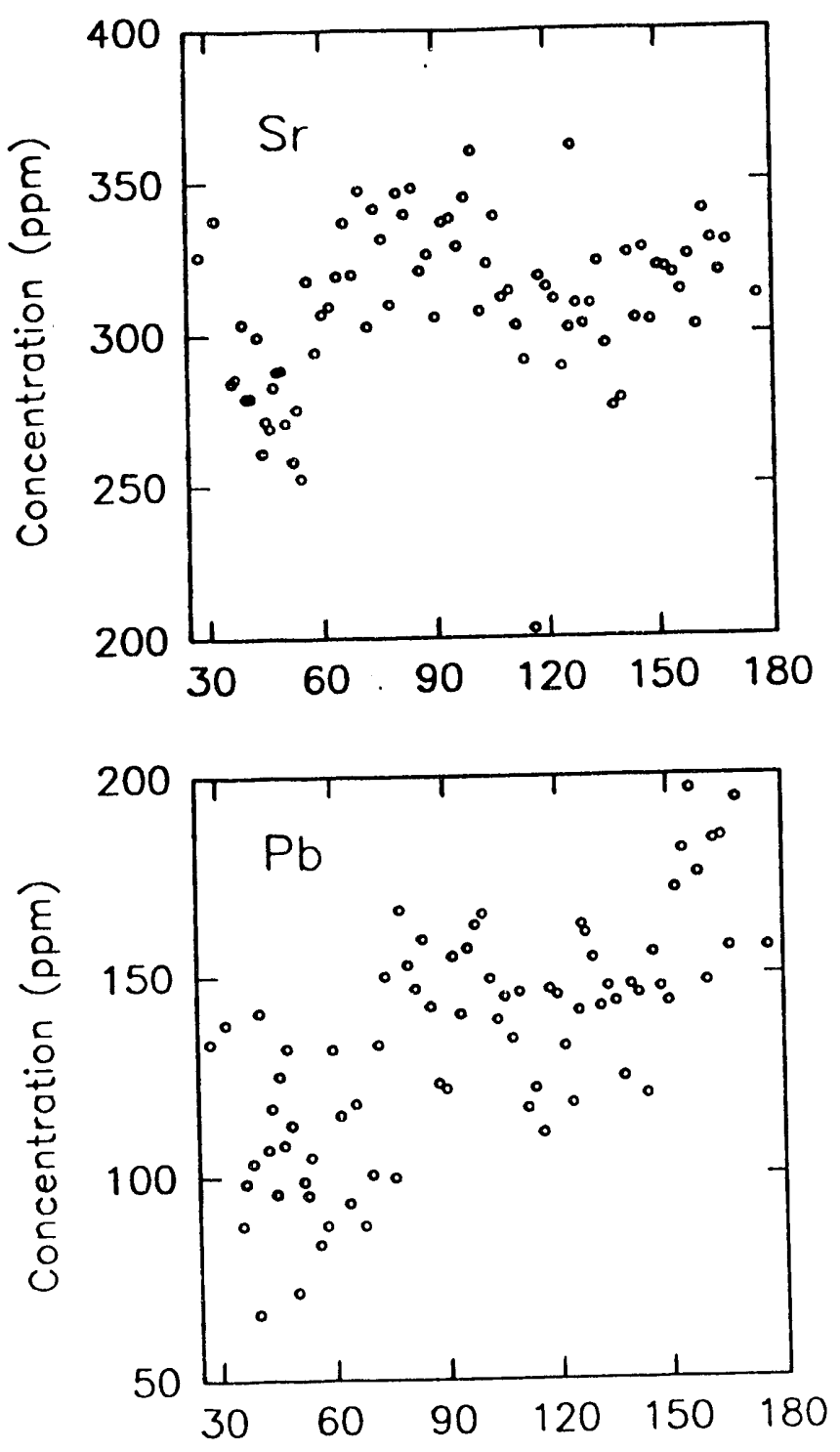
not determined by the calcium content in the ash. It is most likely that this variation is either due to a change in the ash content in the coal used during the run or a change in the temperature in the region where the majority of waste 18 formed. A drop in temperature in the appropriate zone would result in some of the more volatile elements condensing on and/or in the coolside waste.

X-Ray Diffraction - X-ray diffraction analysis was performed on the original Coolside material. The unreacted coolside material contained (in order of abundance) quartz $\left(\mathrm{SiO}_{2}\right)$, mullite (semicrystalline Al-silicate), portlandite $\left(\mathrm{Ca}(\mathrm{OH})_{2}\right)$, and halite (NaCl). One extremely weak peak present in the diffractogram corresponded to gypsum, $\mathrm{CaSO}_{4} \cdot 2 \mathrm{H}_{2} \mathrm{O}$, but presence of this substance cannot be definitely confirmed. As expected, the concentration of halite decreased noticeably in the material that had been stirred in water for one hour and filtered. In a separate experiment on coolside material it had been stirred in water for 1 hour. X-ray analysis showed the water treated material also contained three very small peaks that matched the three most intense peaks of gorgeyite $\left(\mathrm{K}_{2} \mathrm{Ca}_{5}\left(\mathrm{SO}_{4}\right)_{6} \cdot \mathrm{H}_{2} \mathrm{O}\right)$. The constituents of the original coolside material appear consistent with a mixture of fly ash, hydrated lime, $\mathrm{NaOH}$, and flue gas desulfurization products. The rather high Nacl content of the Coolside material was unexpected.

scanning Electron Microscopy - Coolside materials were examined under the Scanning Electron Microscope (SEM), and were found to contain three distinctive components. Aluminum and silicon rich spheres and ellipsoids 10 to $20 \mathrm{um}$ in diameter are the most common constituent of the coolside material. These spheres are typical for the inorganic component of fly ash. The Ca rich portion of the coolside waste is arranged in agglomerates of $\mathrm{Ca}(\mathrm{OH})_{2}$ that range widely in size $(2 \mu$ to $50 \mu)$ and typically 
contain smaller Al-Si fly ash spheres: The final constituents of the Coolside material are large $(50 \mu)$ perforated spheres of carbonaceous material that are also common in fly ash. The carbonaceous material contains the Nacl as small $(2 \mu)$ subhedral grains included in the carbonaceous matrix. of particular interest was the small size of the crystallites composing the $\mathrm{Ca}(\mathrm{OH})_{2}$ agglomerates. X-ray amorphous Al-Si-Fe oxides and oxyhydroxides commonly observed in fly-ash are likely also. present.

A simple experiment was performed to assess the reactivity of the Coolside material. A sample consisting of $65 \%$ Coolside waste was mixed with $35 \% \mathrm{H}_{2} \mathrm{O}$ and aged for two days at room temperature. The sample was dried in an oven at $65^{\circ} \mathrm{C}$ overnight and pulverized for $x$-ray diffraction analysis. Preliminary results indicate considerable change in the crystalline components even after a reaction time of two days.

\section{PILOT PLANT COOLBIDE WABTE BAKPLES}

The X-Ray Fluorescence analysis of the four pilot plant test materials is contained in Table 5 and the proximate and ultimate analyses are shown in Table 6.

The concentration of the elements determined by PIXE/PIGE in the pilot plant samples are compared with the average values for the Coolside Run 3 and Run 1 samples in Table 7 . It is clear from the concentrations of aluminum and iron that the ash content of the pilot plant material is lower than the coolside materials. on the other hand, the calcium content of the pilot plant material is more than twice the calcium concentration found in the coolside waste. The sodium concentration of the pilot materials is consistent with the operating parameters of the pilot production tests; c.a. 2 wt. $\%$ in test 1 and 2 and 0.18 wt. $q$ in test 3 and 4 . While the difference in the concentration of 


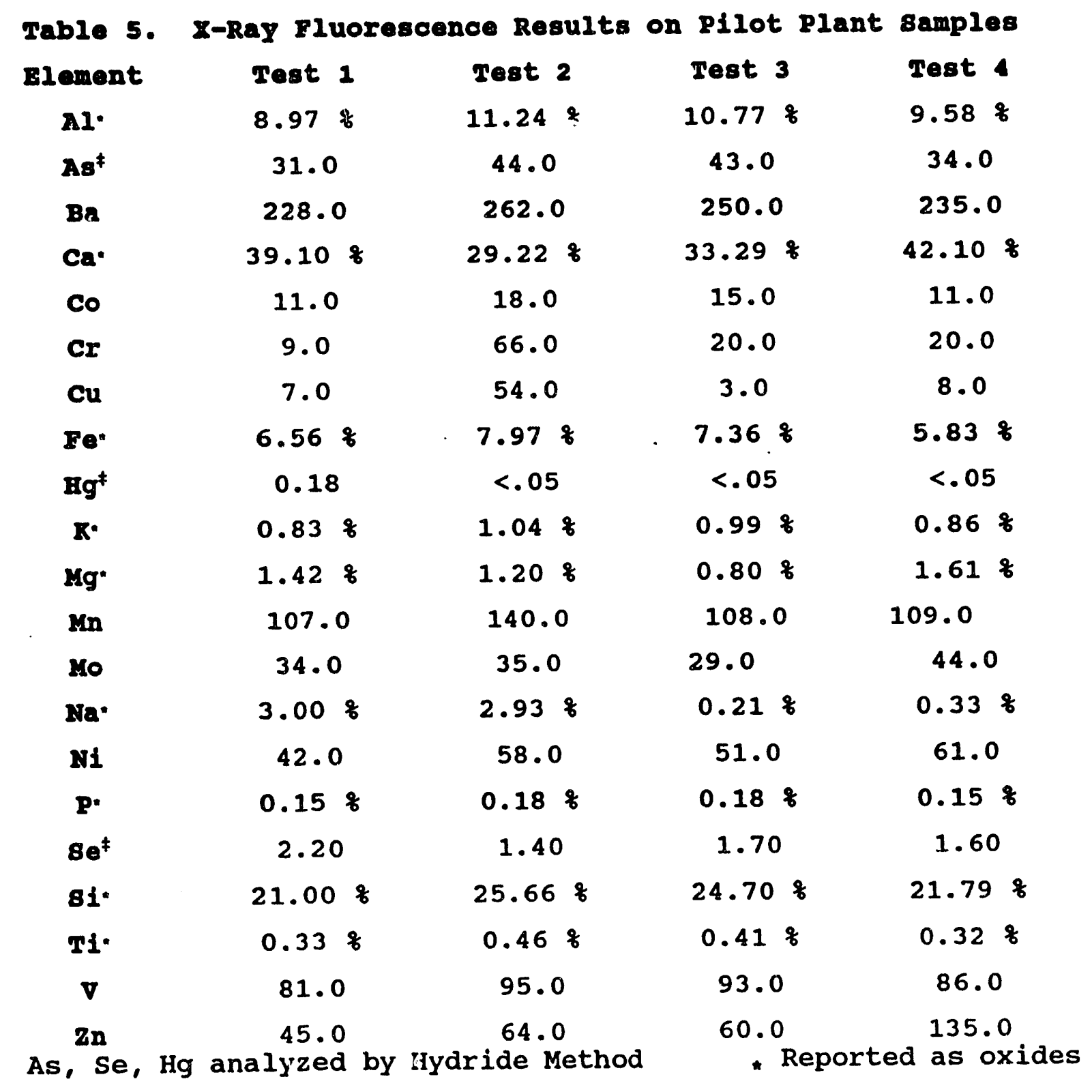


Table 6. Proximate and Oltimate Analyses

$\begin{array}{cccc}\text { Pilot } & \text { Pilot } & \text { P1lot } & \text { P1lot } \\ \text { Test } * 1 & \text { Test } \# 2 & \text { Test } \# 3 & \text { Test } * 4\end{array}$

Proximate

Molsture

$$
4.31 \%
$$

$1.75 \%$

2.99 \%

4.118

Volatile

$11.00 \%$

$11.40 \%$

$6.90 \%$

10.908

Ash

$84.75 \%$

85.74 \&

90.148

84.83 \%

Fixed C

$<.10 \%$

$1.10 \%$

$<.10$ \&

$.20 \%$

\section{oltimate}

$\begin{array}{lrrrr}\text { Carbon } & 1.66 \% & 1.51 \% & 1.36 \% & 1.32 \% \\ \text { Hydrogen } & 1.21 \% & .92 \% & .95 \% & 1.36 \% \\ \text { Sulfur } & 7.72 \% & 8.21 \% & 9.52 \% & 5.90 \% \\ \text { Nitrogen } & .48 \% & .53 \% & .48 \% & .55 \%\end{array}$

most of the trace elements can be attributed to the lower ash content of the pilot samples, it is interesting to note that the scandium concentration of the Coolside samples is considerably lower than the values observed in the pilot materials and the strontium concentration of the Coolside and pilot samples is nearly equal. The strontium values can be attributed to the higher calcium content of the pilot materials; one would expect enhanced strontium with higher calcium. Although we have no explanation for the high scandium values in the pilot materials at this time, an analysis of the lime used in the pilot plant runs may account for the high Sc values. 
Table 7. Elemental Composition of pliot plant and Coolside wastes by Instrumental PIXE/PIGE Analysis.

Element Test 1 Test 2 Test 3 Test 4 Run 3 Run 1

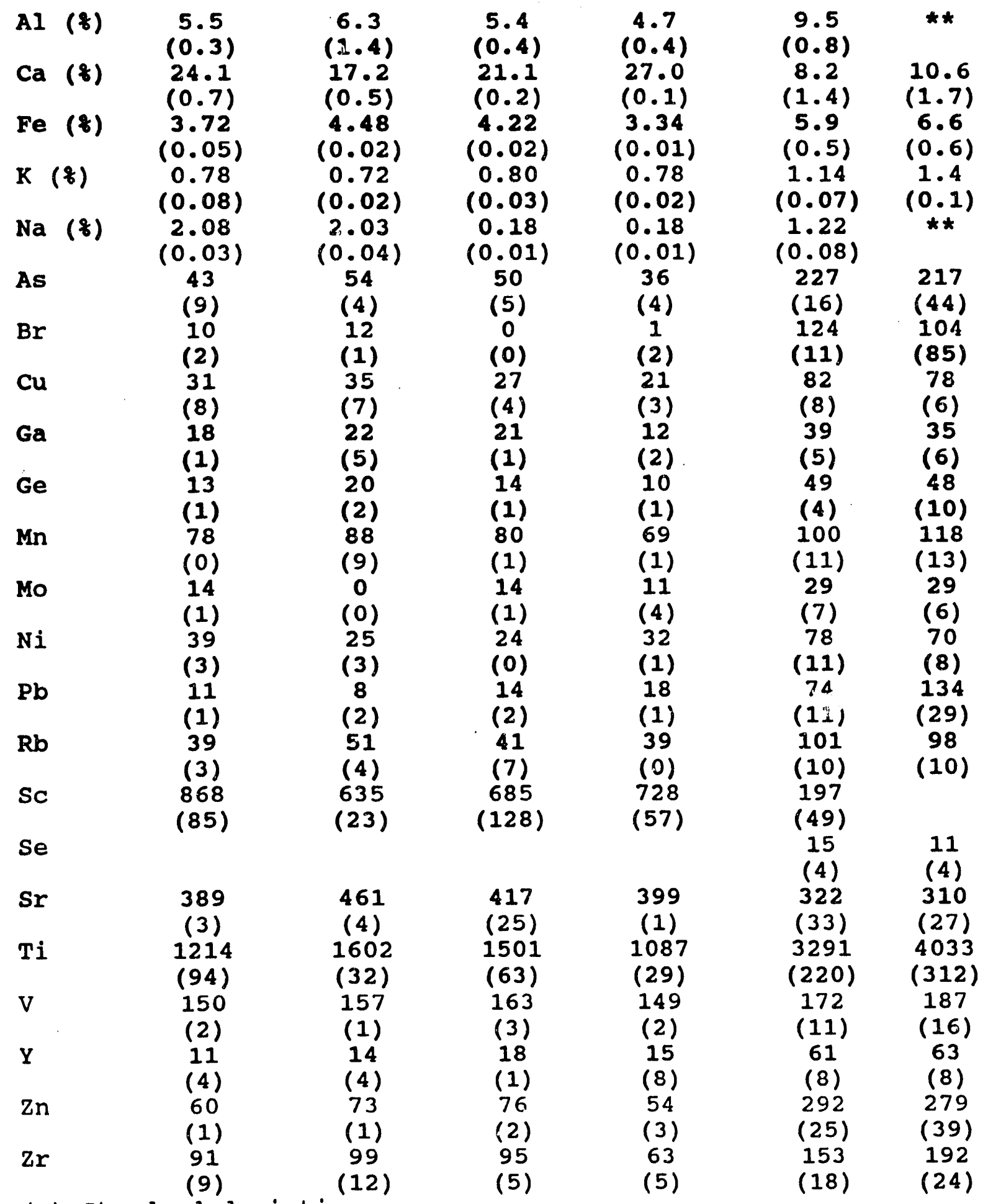




\section{UBTABX 2.3 - GEOTECATICAI CRNRACTERI8ATION OF THE TASTE}

Geotechnical tests were performed to characterize the physical properties of the coolside waste and to examine potential disposal schemes and uses of the material. Index tests were performed to develop classificational data and identify general engineering characteristics of the waste. Tests were performed to determine structural properties of the waste and to develop specific information that would be required for designing and constructing engineered facilities using the waste. These tests were performed to assess the compaction, shear and bearing strength, permeability, and swelling characteristics of the waste. All tests were generally performed following procedures of the American Society for Testing Materials (ASTM, 1988).2 Although the testing program is still in progress, test results obtained to date and preliminary analysis of those results are described in following sectio:is.

\section{IRDEX PRCPERTIES AND CLAB8IFICATION}

Index tests, which included liquid and plastic limits, specific gravity, and grain-size analysis, were performed on six samples of the coolside waste obtained from different experimental runs of the process. These tests were performed in accordance with ASTM methods D 4318-84, D 854-83, and D 422-63 (1988), respectively. Results of these tests are summarized in Table 8 . The crolside waste, as shown by the liquid and plastic limit data, is non-plastic. The apparent specific gravity of the particles is less thai that of many typical soils. Specific gravity of the six samples averaged 2.53. Typically, specific gravity of soils range from 2.60 to 2.85 . Percent finer (by

\footnotetext{
${ }^{2}$ American Society for Testing Materials (ASTM); (March 1988), "Joil and Rock, Building stones: Geotextiles," Volume of 04.08 , Section 4 .
} 
weight) than a U.S. No. 10 sieve wàs 100 percent, that is, 100 percent of the material passes this sieve size. About 94 to 96 percent of the material passes a No. 200 sieve. Hence, the waste is a fine-grained material. Although variations in the processing runs occurred, the particle-size composition of the material is consistently uniform. The silt-size fraction of the six samples ranges from 75 to 85 percent and averages about 80 percent. Sandsize and clay-size particles compose about 5 percent and 15 percent (<0.005 mm-size), respectively, of the naterial matrix. only about 6 percent of the material consists of particles smaller than $0.002 \mathrm{~mm}$.

Based on the Unified Soil Classification System (ASTM D 2487-85, 1988), the waste is classified as $\mathrm{KL}$, or may be described as a silt, or silt with sand. Based on the AASHTO Classification system, the waste is classified as A-4(0). Normally, silts are very susceptible to frost penetration. Problems involve vertical and horizontal expansion of the material during freezing. Shear strength may decrease during thawing in seasonal frost areas. Moreover, liquefaction may readily occur in these types of soils when rapidly loaded. Although silty soils are typically very susceptible to these problems, the coolside waste may not behave in a similar manner (except during initial placement) because the material tends to hydrate and stiffen as it ages. This aspect is discussed in the following sections.

\section{GTRUCTURAL PROPERTIES}

Compaction - Compaction is the process by which a soil mass consisting of soil particles, air, and water is reduced in volume by the application of loads. The process involves the expulsion of air. Compaction decreases permeability, volume, and compressibility and increases shear strength. Hence, compaction characteristics are an important aspect in devising disposal schemes and in considering the use of the coolside waste in 
engineered facilities. In the compaction of soils, the maximum dry density (the mass of solid particles per the total volume of soil) and optimum moisture content are a function of the. compactive effort, or the energy supplied to compact the material. To examine the relationships between dry density and compactive effort, and optimum moisture content and compactive energy, laboratory compaction tests were performed at different compactive energies. These tests were performed at modified compaction (ASTM D 1557-78), standard compaction (ASTM D 698-78), and a low energy compactive method. ${ }^{3}$ Compactive energies of these tests were 237,$356 ; 60,438$; and 12,133 meter-kilograms per cubic meters. In addition to the three dynamic compactive energies, compaction tests were performed using static compaction. These tests were performed in an attempt to simulate the compactive action of the tracks of a caterpillar D9L tracktype tractor." The static compaction tests were performed at a stress of $117 \mathrm{kPa}--$ the contact stress of the tracks of this equipment.

Typical compaction test results obtained for the Coolside sample cS-3 are illustrated in Figure 6. Identical results (not shown) were obtained for Coolside sample CS-1. As the compactive energy increases, the maximum dry density increases and optimum moisture decreases. Maximum dry density ranges from $7.79 \mathrm{kN} / \mathrm{m}^{3}$ at static compaction to $12.10 \mathrm{kN} / \mathrm{m}^{3}$ at modified compaction. Dry density of the coolside material in a loose, dry state is $5.72 \mathrm{kN} / \mathrm{m}^{3}$. Hence, the dry density obtained from the static compactive effort is only about 36 percent higher than the loose-state density.

\footnotetext{
${ }^{3}$ Hopkins, T.C.; (January 1988), "Shear strengths of Compacted Shales," Research Report UKTRP-88-1, University of Kentucky Transportation Center, College of Engineering, Lexington, Kentucky.

'Caterpillar Tractor Company; (1981), "Caterpillar Performance Handbook," Edition 12, Peoria, Illinois, U.S.A.
} 
Variation of the maximum dry density of sample cs-3 with compactive energy is illustrated in Figure 7. The maximum dry density $\left(10.80 \mathrm{kN} / \mathrm{m}^{3}\right)$ of the Coolside material obtained from standard compaction is about 1.9 times the dry density of the material in a loose state. However, the maximum dry density at modified compaction is only about 1.12 times the maximum dry density at standard compaction. Hence, a four fold increase in compactive energy above standard compactive energy increases the dry density only 12 percent. Consequently, efforts to compact the Coolside material to a dry density higher than the maximum dry density obtained from standard compaction would probably be uneconomical. However, the compactive energy selected would depend on the specific site variables, such as land cost, cost of compaction equipment operation, haul distances, and availability of land for disposal. Economic evaluation of these factors would be required at a given site to select the most economical compaction energy.

Variation of optimum moisture content and compactive energy for sample cs-3 is illustrated in Figure 8. At standard compaction, the optimum moisture content is about 36.5 percent. Compaction of the coolside material could pose a problem when the water content is higher than the optimum moisture content. Because the Coolside waste contains a large silt content, the material may liquefy under compaction stresses when the water content is greater than optimum moisture content. Based on results obtained from the index tests, 95 to 100 percent of maximum dry density obtained from standard compaction may be achieved using sheepfoot rollers. Compacted lift thickness should be about $15.24 \mathrm{~cm}$ and 4 to 6 coverages may be required. Foot contact stress should range from about 1380 to $2760 \mathrm{kPa}$. A self-propelled Sheepsfoot roller with blade may be desirable so that the material could be spread and compacted at the same time. Alternatively, rubber tire rollers may be used. In this case, the compacted lift thickness of 25.4 


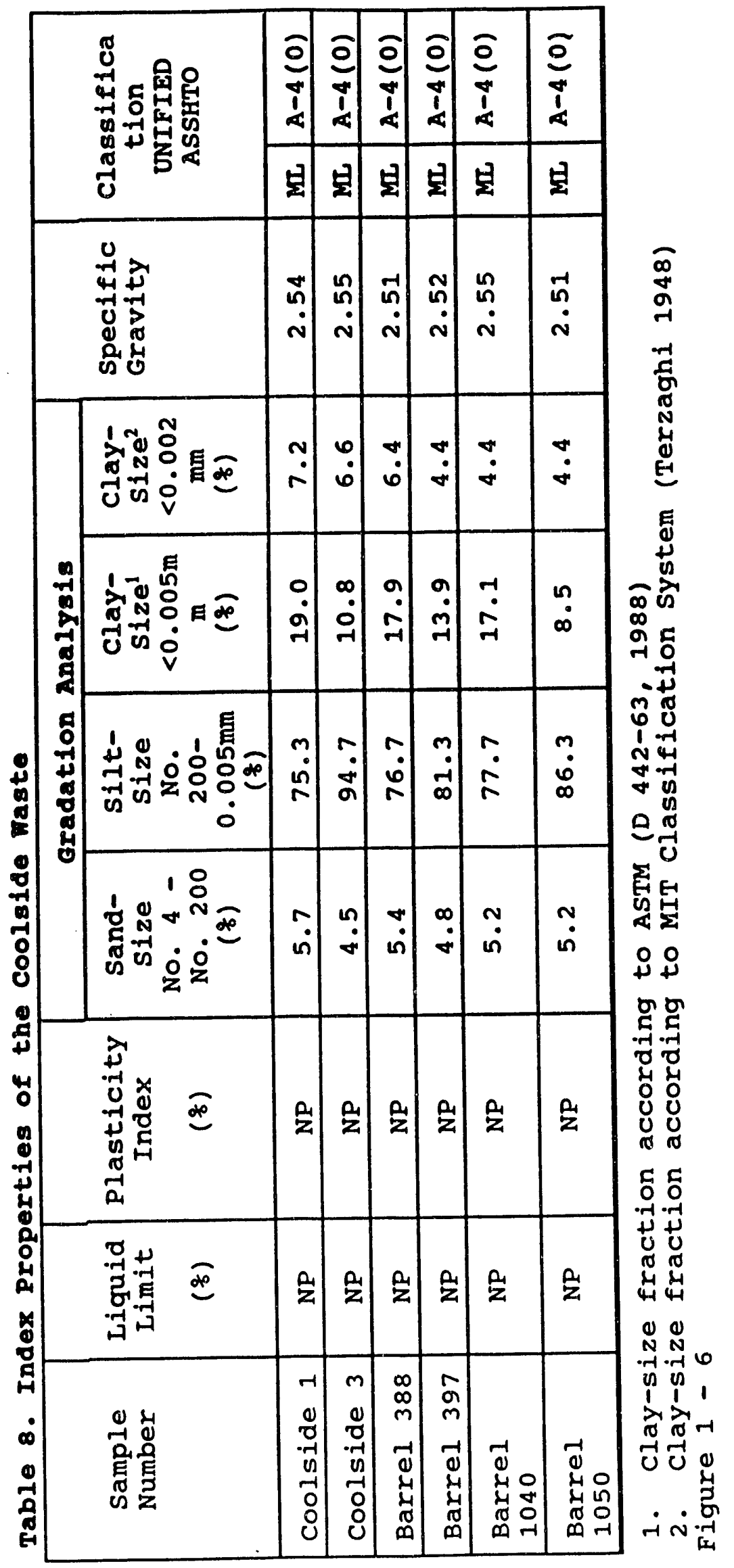




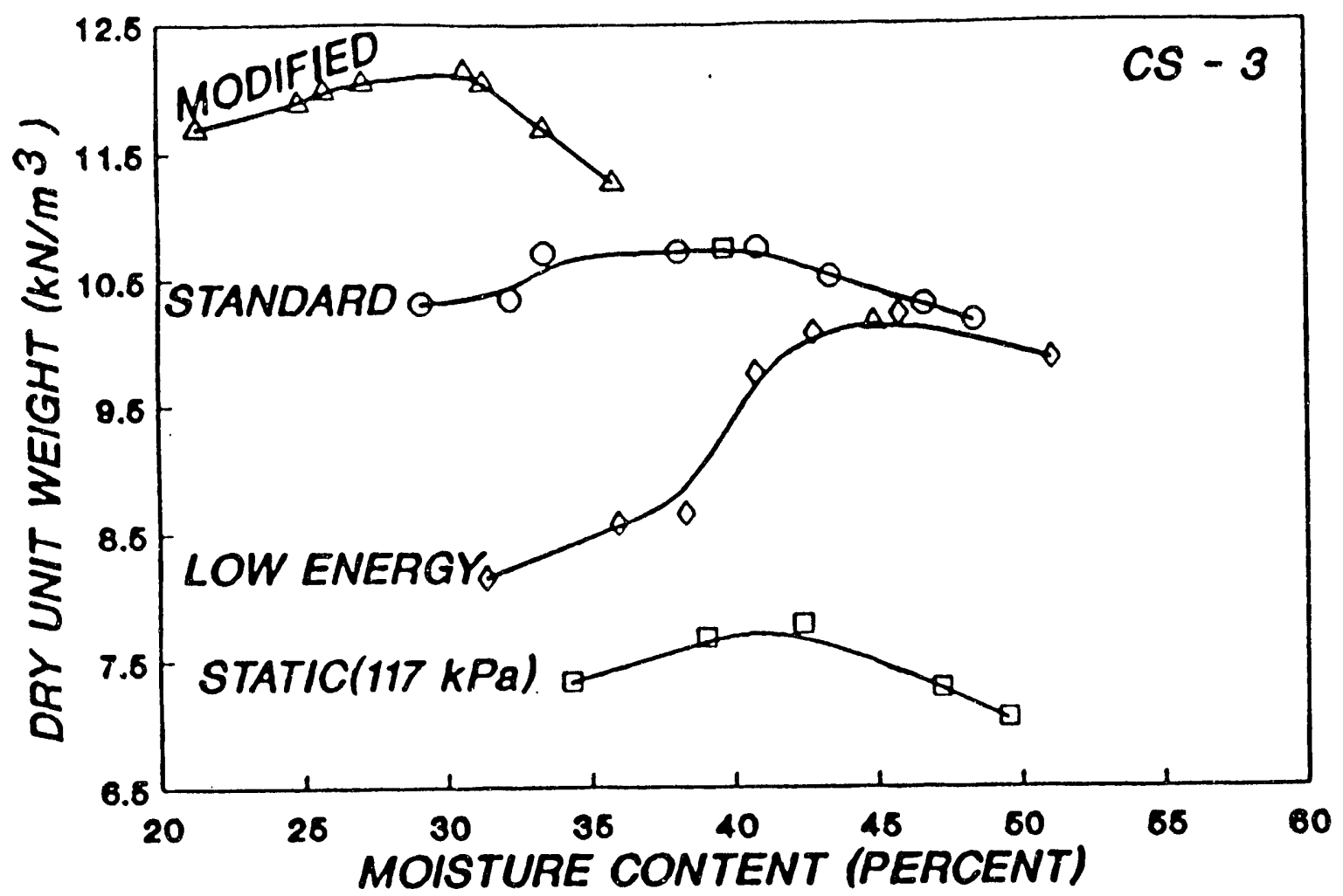

Figure 6 Moisture content-dry density relationships obtained from different compaction methods

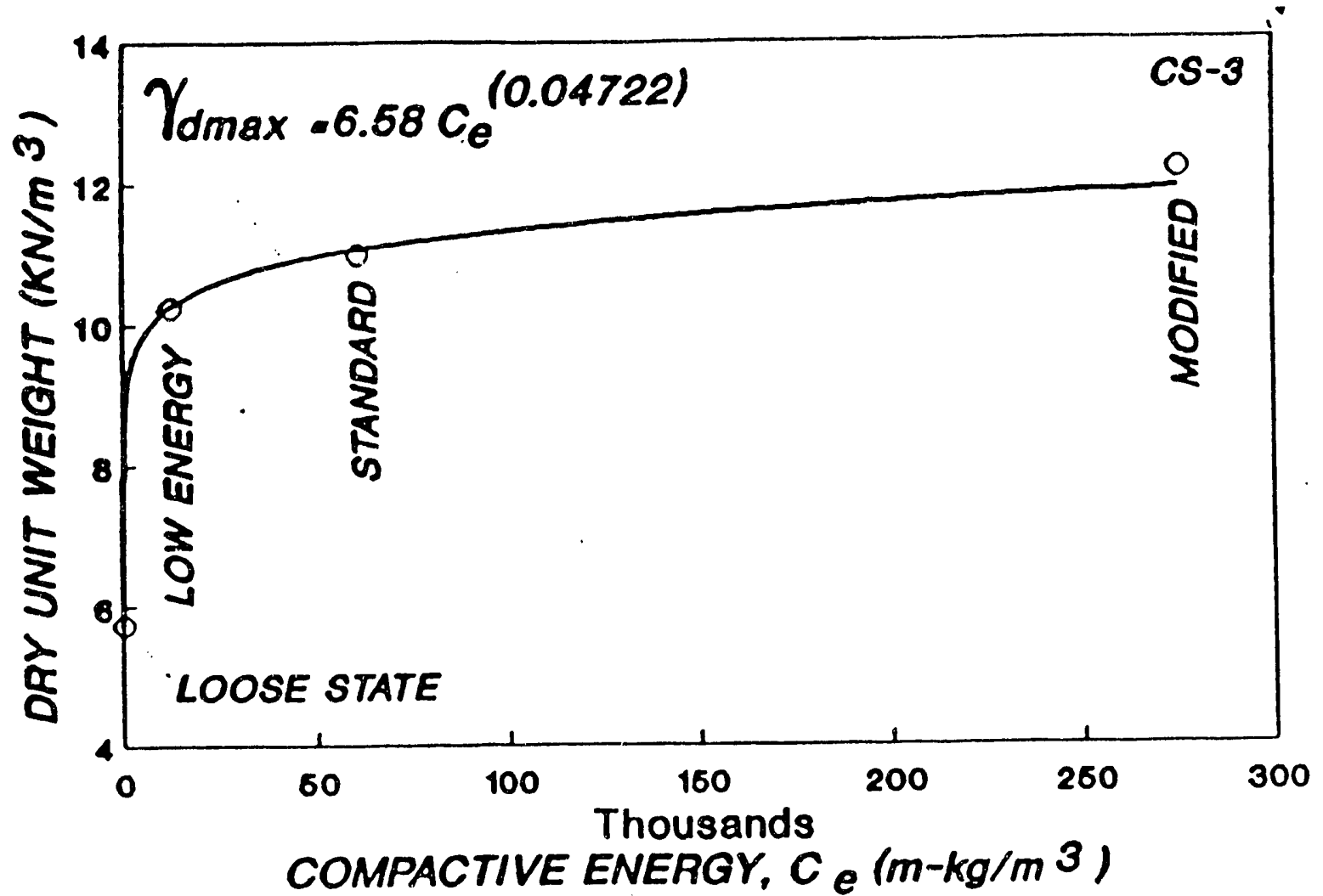

Figure 7. Variation of maximum dry density and compaction energy 


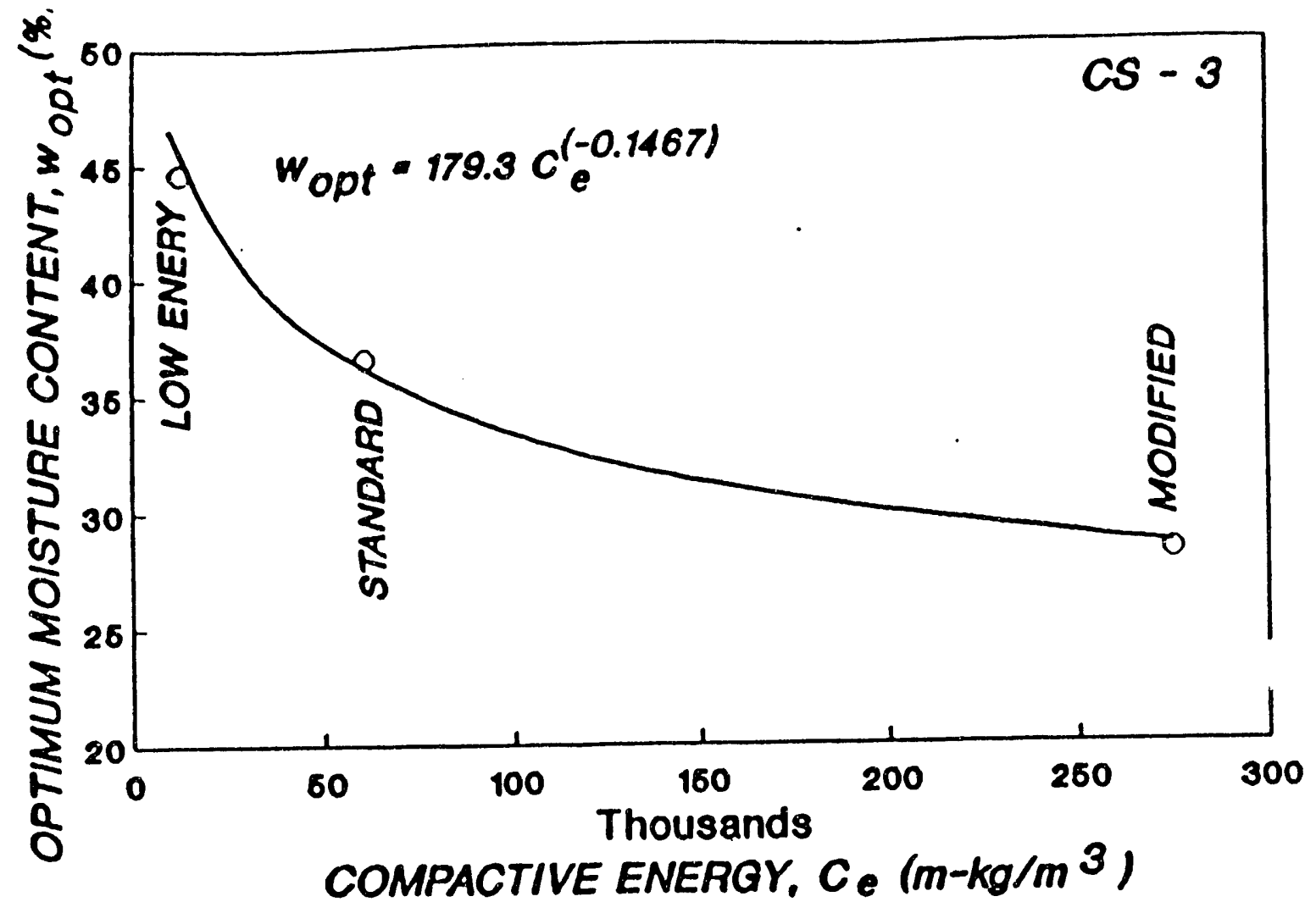

Figure 8. Variation of optimum moisture content and compaction energy

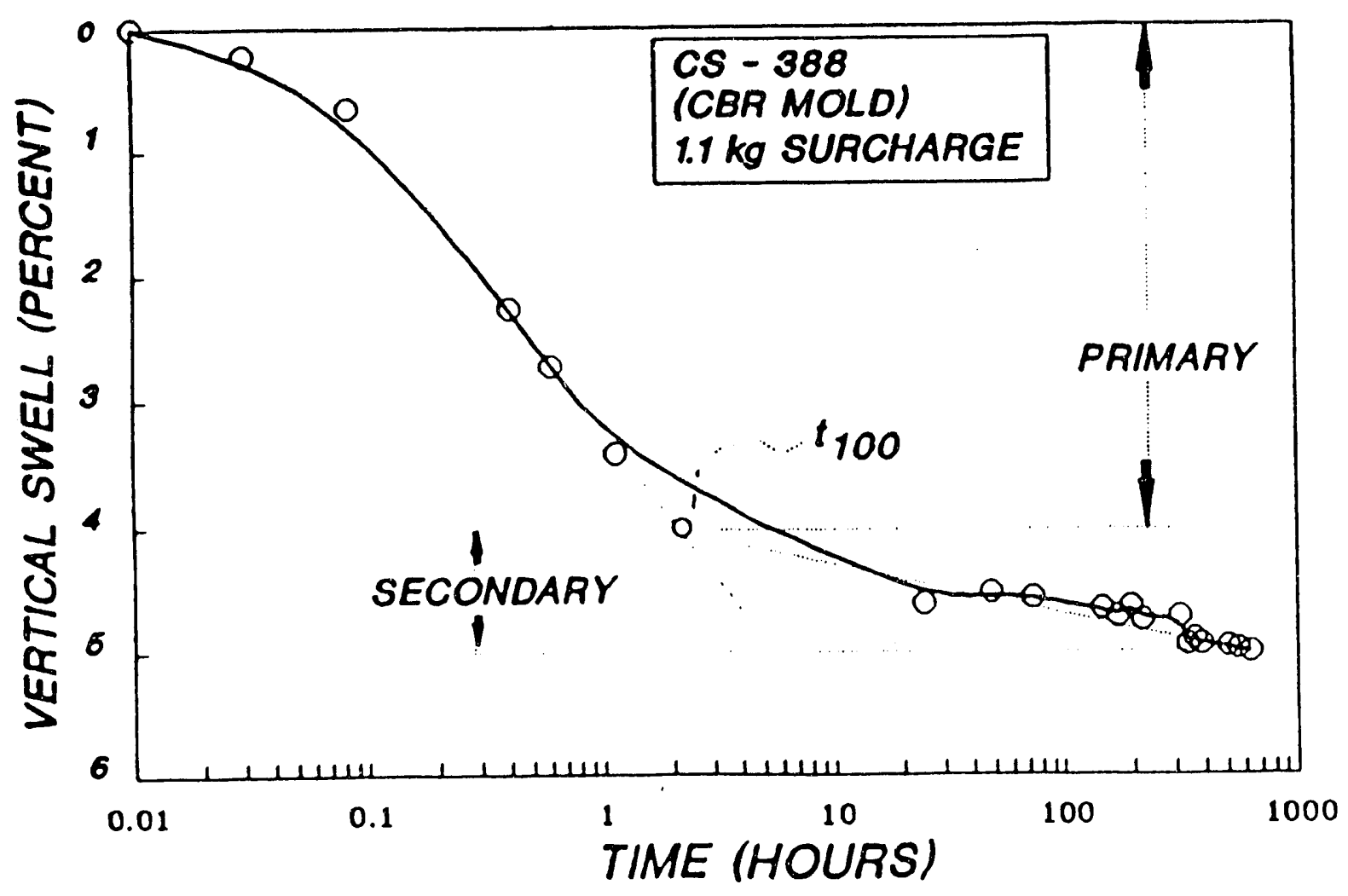

Figure 9. Typical relationship between swell (in percent) of compacted specimens of the Coolside waste and time 
$\mathrm{cm}$ is indicated. About 4 to 6 coverages is required. Large size tires with inflation pressures ranging from about 276 to $345 \mathrm{kPa}$ are desirable to avoid shear and rutting. Field trials at a given site should be performed to insure the proper selection of compaction equipment and to determine desired density states.

swelling Properties - Swelling behavior due to the absorption of water may significantly affect engineered facilities constructed with, or on, soil-like waste materials. Structural foundations placed on waste materials may crack and become unstable. At landfill disposal sites, large differential swelling of the waste material may crack final clay caps used for environmental protection. Embankment slopes constructed with waste materials that are susceptible to expansion when exposed to water may become unstable over a period of time after construction. Magnitude and rate of swelling are important considerations when using waste materials in engineered facilities. Although the time required to complete swelling may be large, little damage may occur if the total magnitude of swelling is small. The total magnitude of swelling may be large but little damage may occur if the magnitude occurs rapidly. Extensive damage may occur when the total magnitude and the time required to complete swelling are large.

To determine the swelling properties of Coolside waste, swelling tests were performed. Two series of tests were performed in oedometers, which commonly are used to perform consolidation tests. A third series of tests was performed in CBR molds. Diameter and height of the oedometer specimens were $6.35 \mathrm{~cm}$ and $2.54 \mathrm{~cm}$, respectively. Diameter and height of the CBR specimens were $15.24 \mathrm{~cm}$ and $11.64 \mathrm{~cm}$, respectively. All specimens were remolded to 95 percent of maximum dry density and optimum moisture content obtained from standard compaction (ASTM D 69878, Method A, 1988). Swelling periods for tests conducted in the oedometer apparatus ranged from about 18 to 21 days. Swelling 
periods of tests performed in the CBR molds ranged from 64 to 79 days. In the first series of oedometer tests, the coolside material was compacted immediately after mixing. After compaction, the tests were started by submerging the specimens (and mold) in water. In the second series of tests, the coolside waste was compacted and the specimen was allowed to age for seven days. The specimens were aged in sealed containers at room temperatures (about $21^{\circ} \mathrm{C}$ ). In the third series, the swelling tests were started after the CBR specimens had aged 0, 7, and 14 days.

since swelling due to the absorption of water is consolidation in reverse, the same theoretical principles (Terzaghi, 1943) that are applied to the analysis of consolidation test data were used to analyze the swelling test data.' A typical swell deflectiontime curve obtained from the oedometer tests is illustrated in Figure 9. The total amount of swell may be divided into two parts: primary swell and secondary swell. Hence, coefficients of primary and secondary swell may be determined from Terzaghi's theory of consolidation (1948) and fitting methods (square-rootof-time and Logarithmic-of-time) described by Terzaghi. The coefficient of primary swell, $c_{p s}$, may be computed from the equation

$$
C_{p s}=\frac{T H^{2}}{t}
$$

where

$$
\begin{array}{ll}
\mathrm{T}= & \text { dimensionless time parameter, which is } \\
& \text { related to percent of primary } \\
& \text { consolidation, } \\
& \text { length of absorption path, }
\end{array}
$$

\footnotetext{
STerzaghi, K.; (1943), "Theoretical Soil Mechanics," John wiley and Sons, Inc., New York, New York.
} 


$$
\begin{aligned}
& t=\text { actual time for a given percent of } \\
& \text { consolidation to occur (in the log } t- \\
& \text { fitting method, } t_{s 0} \text { is the time required } \\
& \text { for } 50 \text { percent of primary consolidation to } \\
& \text { occur and } T \text { equals } 0.197 \text {; in the } v t- \\
& \text { fitting method, } t_{90} \text { is the time required } \\
& \text { for } 90 \text { percent of consolidation to occur, } \\
& \text { and } T \text { equals } 0.848 \text { ). }
\end{aligned}
$$

The coefficient of primary swell is used to estimate the time rate of primary swell.

The coefficient of secondary swell $c_{d}$ may be computed from the equation

$$
c_{d s}=\frac{H}{\Delta s} \log \left(\frac{t_{B \theta C}}{t p}\right)
$$

where

$$
\begin{array}{ll}
H= & \text { height of specimen } \\
\Delta s= & \text { vertical secondary swell observed in the } \\
& \text { test for a specified time interval of the } \\
& \text { secondary swell curve, } \\
t_{s e c}=\quad & \text { time at which the test is terminated, } \\
t p= & \text { time to completion of primary } \\
& \text { consolidation. }
\end{array}
$$

Coefficients of primary and secondary swell of the coolside waste were determined and compared to coefficients obtained for two typical, compacted soils - - a silty clay and a plastic clay from Kentucky -- and a compacted mixture of AFBC waste material and a silty soil. The AFBC material was obtained from a Kentucky oil refinery process referred to as Atmospheric Fluidized Bed 
Combustion. The mixture consisted of 15 percent of AFBC and 85 percent of a silty clay. ${ }^{6}$ The silty clay is classified as CL according to the Unified Soil classification system while the plastic clay is classified as $\mathrm{CH}$.

Results of the swelling tests are summarized in Table 9. Swelltime curves for specimens 388A, 1040B, the plastic clay, and the AFBC-silty clay mixture are compared in Figure 10 . In the first series of oedometer tests, where no aging was permitted and no surcharge weights were used, the total swell of the four specimens ranged from about 10 to 23 percent. Primary swell ranged from 8 to 16 percent. Secondary swell ranged from 0.2 to 6.5 percent. In comparison, total values of swell of two typical, compacted Kentucky soils were 4.6 and 12.5 percent. Primary values of swell were 4.1 and 12.1 percent, respectively, as shown at the bottom of Table 9. Hence, swelling magnitudes of the Coolside compacted specimens (no aging) are larger than those of the two typical clays. However, as shown in Table 9, the magnitudes of swell are less than the swelling magnitude of a compacted mixture of an AFBC waste and soil.

The time at which the magnitude of swell occurs during the life of an engineered facility may be more important than the magnitude of swell. As shown in Table 9, the coefficients of primary swell of the Coolside compacted specimens are much greater than those of the compacted typical soils and the AFBCsilty clay mixture. The coolside coefficients, $c_{p s}$, of the specimens where no aging was allowed ranged from about 11 to 102 $\mathrm{cm}^{2} /$ day and averaged about $60 \mathrm{~cm}^{2} /$ day. The average value is some 4 to 300 times larger than the values of the typical soils and

${ }^{6}$ Hopkins, T.C., Hunsucker, D., and Sharpe, G.W.i (October 1988), "Highway Field Trials of Chemically Stabilized Soil. Subgrades," proceedings of the ohio River valley Soils Seminar XIX, Lexington, Kentucky. 
about 120 to 150 times larger than the value obtained for the AFBC-silty clay mixture. Hence, primary swell of the Coolside specimens occurs (no aging) fairly fast when no aging is allowed prior to soaking.

As indicated by results (Table 9) of the second series of swelling tests, the aging of the coolside compacted specimens tends to change the swelling characteristics of the material. In this series, no surcharge weights were used. Total magnitudes of swell of specimens aged for 7 days before soaking ranged from 1 to 5 percent. Hence, the aging process appears to decrease the swelling amounts significantly. These swelling magnitudes were generally less than the magnitudes of swelling of the two typical soils and the AFBC-soil mixture. However, coefficients of primary swell decreased. Values of $C_{p s}$ of the seven day-aged specimens ranged from 0.11 to $0.30 \mathrm{~cm}^{2} /$ day. The average value of $c_{p a}$ is some 315 times smaller than the average value of the non-aged specimens. The third series of tests were performed on CBR-size specimens. Four (specimen numbers 388A, 1040B, 388C, and 1040D) of the six specimens were not aged prior to soaking.

These four tests were a repeat of the first series of tests, except larger specimens weie used and surcharge weights were placed on the swelling specimens. A surcharge weight of $1.13 \mathrm{~kg}$ was placed on specimens numbered 388A and 1040B. The applied pressure was about $0.7 \mathrm{kPa}$. Magnitudes of swell for these two specimens were about 5 and 9 percent, respectively. These values were much less than swell magnitudes (10-23 percent) observed in the first series where no surcharge was used. The swell magnitudes were even smaller when the surcharge weight was increased to $5.67 \mathrm{~kg} \mathrm{--}$ an applied pressure of about $3.4 \mathrm{kPa}$. In this case (specimens numbered $388 \mathrm{C}$ and 1040D), swell magnitudes were 1.6 percent and this value was much smaller than the values observed for the first series of tests and specimens $388 \mathrm{~A}$ and 


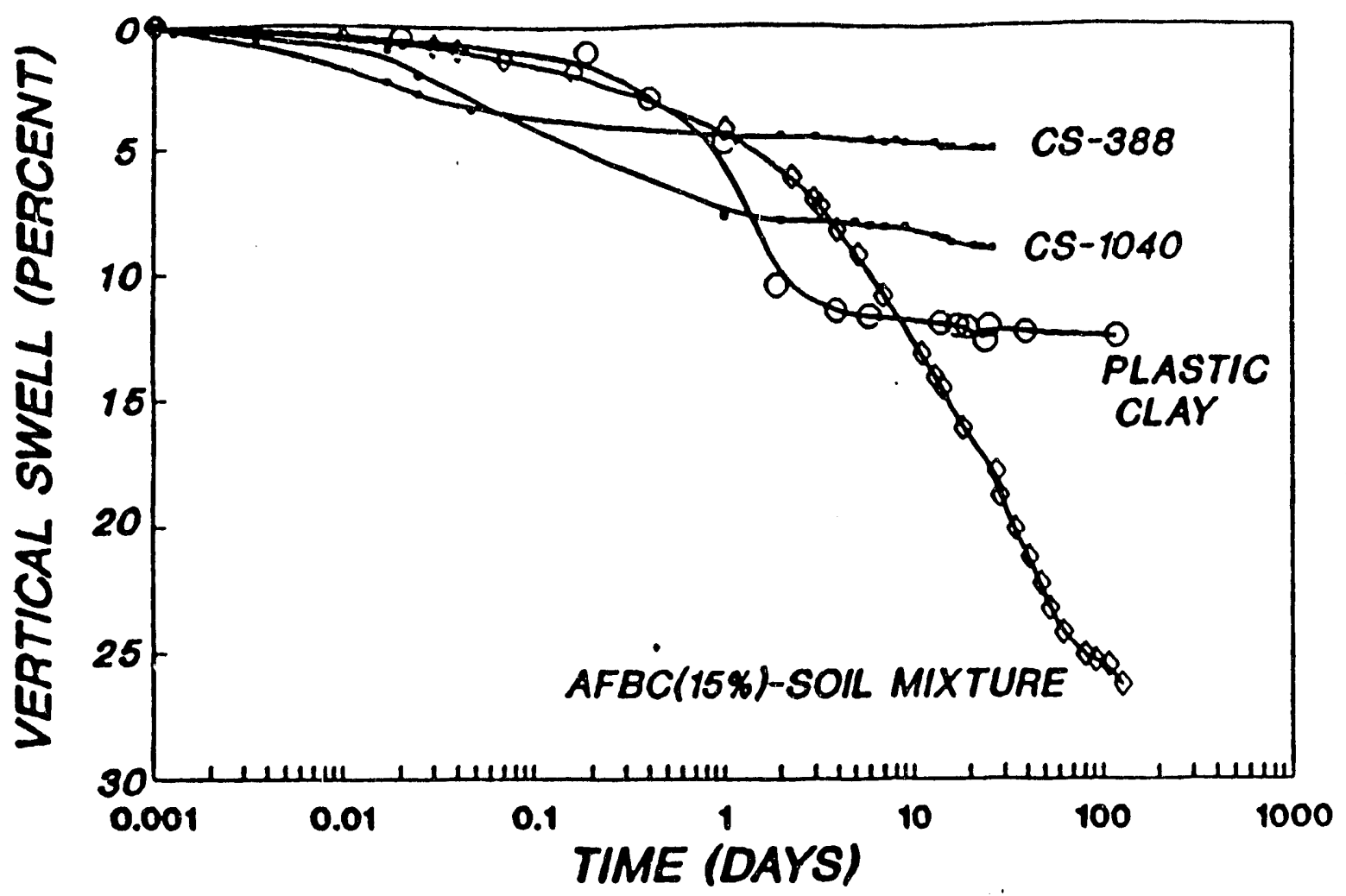

Figure 10 Comparison of the magnitudes and rates of swell of compacted specimens of the Coolside waste, two typical clays, and soil-AFBC mixture

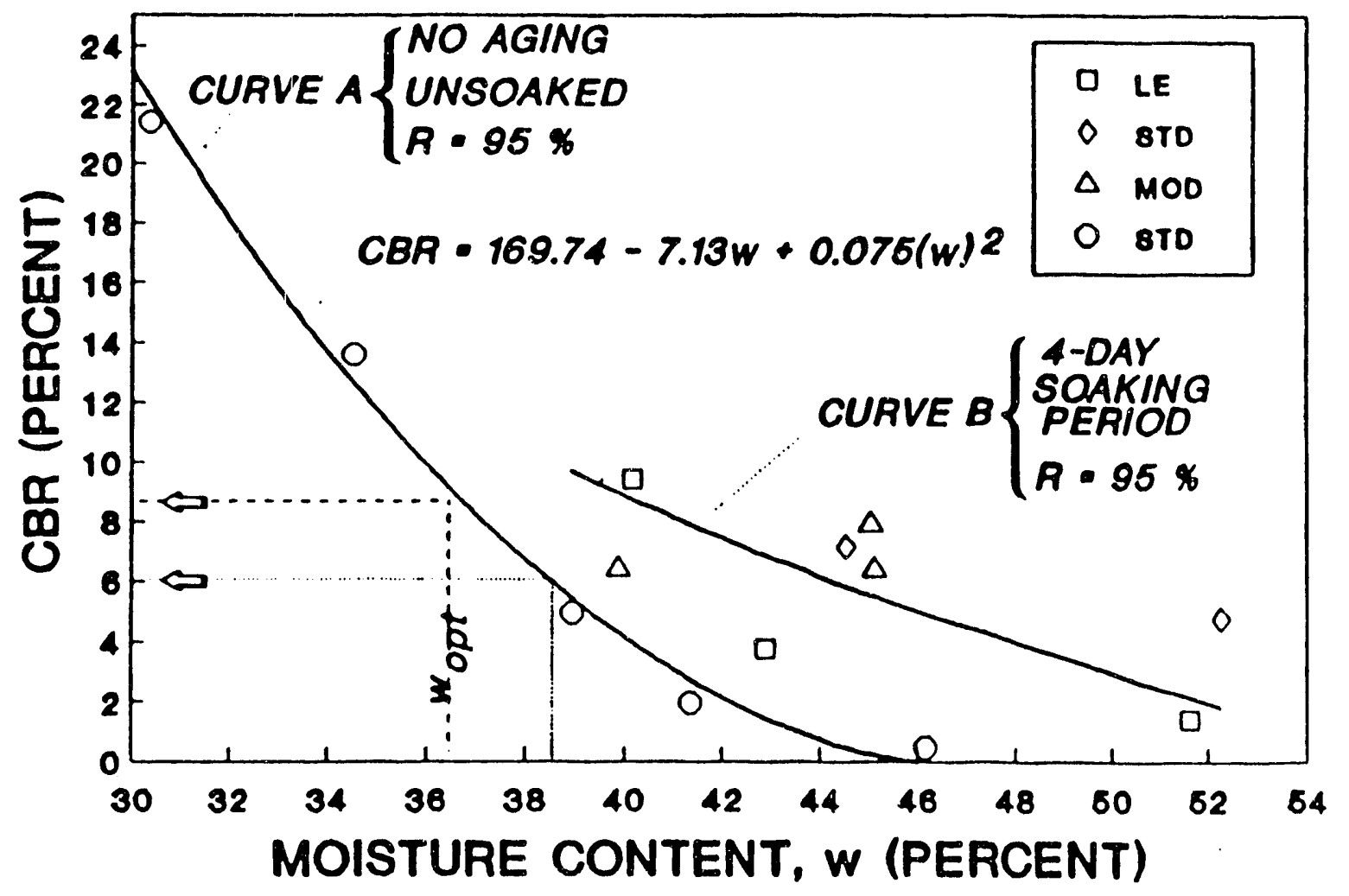

Figure 11 Relationships of CBR strengths of compacted specimens of the Coolside waste and molding moisture 
1040B. These results indicated that the magnitude of swell decreases with increasing surcharge pressure. Coefficients of primary swell for the four tests ranged from 39 to $458 \mathrm{~cm}^{2} /$ day and averaged about $227 \mathrm{~cm}^{2} /$ day. The hi.gh values of the coefficients of primary swelling observed for the non-aged, CBRspecimens were similar to values observed in the first series of tests, although they were approximately some 3 to 4 times larger.

Specimens numbered $1040 \mathrm{E}$ and $388 \mathrm{~F}$ were aged 7 days and 14 days, respectively, before soaking. Additionally, surcharge pressures of $0.7 \mathrm{kPa}$ and $3.4 \mathrm{kPa}$, respectively, were applied to the swelling specimens. The combined effects of aging and surcharging caused large decreases in the magnitudes of swell. Specimen $1040 \mathrm{E}$ swelled 0.2 percent while specimen $388 \mathrm{~F}$ swelled only 0.1 percent. These values are much less than swell magnitudes observed for the two typical soils, or the AFBC-silty clay mixture. However, the coefficients of primary decreased from values ranging from 39 to $458 \mathrm{~cm}^{2} /$ day to values ranging from 2.3 to $11 \mathrm{~cm}^{2} /$ day. Although the primary swell coefficients decrease, the swell magnitudes were very small.

In all cases, the coefficients of secondary swell of the compacted specimens of coolside waste were low and they ranged from 0.0 to 0.009 . These values are similar to those observed for the two typical soils and much lower than values observed for the AFBC-silty clay mixture.

shear strength - The short-term and long-term stabilities of geotechnical facilities constructed with, or on, the coolside waste will depend on the shear strength of the coolside waste at different times of aging. Since construction equipment must operate on the material, the initial bearing, or shear strength, is important to insure mobility and efficient operation of construction traffic. A knowledge of the long-term shear strength 


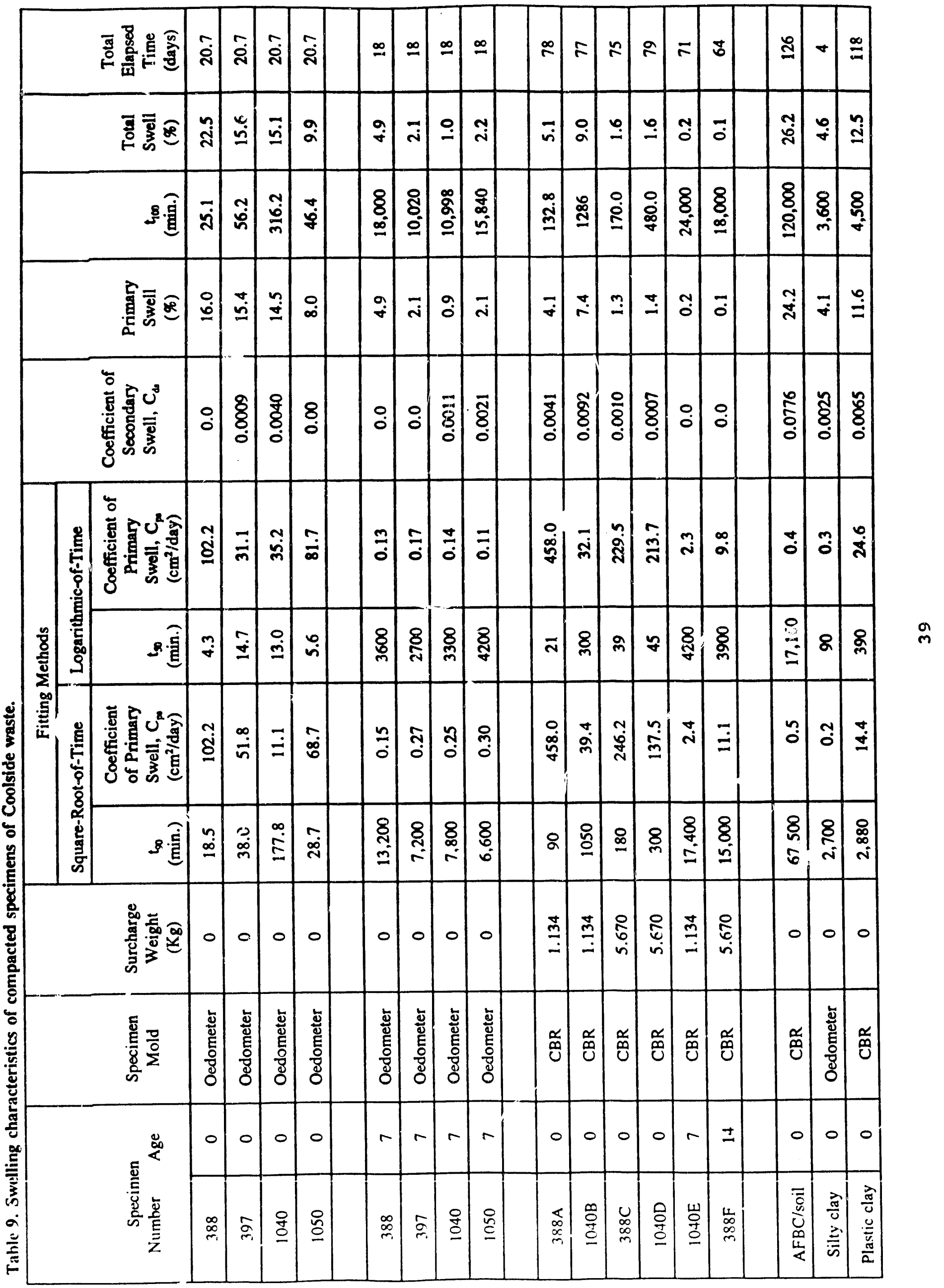


of the material is vital to maintaining stable structures throughout their useful lives. Although the shear strength testing program is in an initial testing stage, a few test results are described below.

Bearing strength - In the disposal of the Coolside waste, or in constructing geotechnical facilities with the waste, the material will be subjected to construction traffic loadings. The mobility and efficient operation of construction equipment on the material will depend on the initial bearing strength of the compacted material. To avoid deep rutting, or shear failures, the compacted material must have some initial minimum bearing strength. The initial bearing strength was determined by performing CBR (California Bearing Ratio -- ASTM D 1883-87) tests on unsoaked, compacted specimens. No aging of the specimens was allowed. Since initial bearing strength is very much depindent on the molding (or placement) water content and density, this series of Coolside specimens were remolded at different moisture contents and penetrated immediately after compaction. The specimens were remolded to 95 percent (relative compaction, R) of standard maximum dry density.

The relationship between $C B R$ strength and molding moisture content for this series of tests is represented by curve $A$ in Figure 11. As the molding moisture content increases (for a constant value of molding dry density), the CBR strength decreases. At four percent above the optimum moisture content (40.8), the CBR value is 3.7 percent. To avoid deep rutting, or tire sinkage, Hopkins ${ }^{7}$ has shown that the CBR strength of a bearing media, when subjected to dual-wheel tire contact stresses of $552 \mathrm{kPa}$, must be greater than about 6. At a CBR value of 6 , the placement water content is about 38.8. Hence, the placement moisture content should not be greater than 2 percent about

\footnotetext{
${ }^{7}$ Hopkins, T.C.; (1992), "Bearing Capacity Analysis of Pavements," Research Report KTC-91-8, University of Kentucky Transportation Center, College of Engineering, Lexington, Kentucky.
} 
optimum moisture content. However, to limit tire sinkage, the placement water content should not exceed optimum moisture content.

In the second series of CBR tests, the specimens were soaked for a period of 4 days, as specified by ASTM Method D 1883-87 (1988). The specimens were compacted at 95 percent of maximum dry densities obtained from modified, standard, and low-energy compaction tests. The approximate relationship between moisture content (after soaking) and CBR strength of these tests is represented by Curve $B$ in Figure 11. Apparently, during the four-day soaking period, the coolside specimens hydrated and gained strength. CBR values of these tests are greater than the CBR values of curve $A$ (non-aged specimens). To confirm this finding, and to determine the effect of aging (during soaking) on the CBR strength of compacted Coolside waste, CBR tests were performed on specimens identified as CS-388A and CS-388C (See Table 9). ..... specimens had been remolded to 95 percent of standard maximum dry density and optimum moisture content. The specimens were not aged prior to soaking. The CBR value of specimen CS-388A, which was soaked for 78 days, was 133. The CBR value of specimen CS-388C after soaking for 75 days, was 440 . Hence, the coolside material hydrated and gained enormous strength during the soaking period.

Triaxial strength - The triaxial testing program consists of performing unconfined compression tests (UC), unconsolidatedundrained triaxial compression tests (UU), and consolidatedundrained triaxial compression tests with pore pressure measurements (CU/WPP). Although the triaxial testing program is in initial stages, a few results obtained from UC-and UU-tests are described below.

Unconfined compression tests (ASTM D 2166-85) were performed on remolded specimens to examine the effects of time of aging on strength. All specimens were remolded to 95 percent of standard maximum dry density and optimum moisture content. The specimens 
were aged in sealed containers at room temperature $\left(\approx 21^{\circ} \mathrm{C}\right)$. Two series of tests are being performed. The first series consists of performing the unconfined tests at different aging times in an unsaturated state. The second series consists of performing the tests on specimens that had been saturated during permeability testing. The relationship between unconfined strength, $q_{u}$, and time of aging is shown in Figure 12. The unconfined strength increases from a value of about $252 \mathrm{kPa}$ at a seven-day aging period to about $8984 \mathrm{kPa}$ for an 188-day aging period, that is, the strength gain at the end of about 6 months is some 35 times the seven-day strength.

Unconsolidated-undrained triaxial tests (ASTM D 2850-87) were performed on unsaturated, aged specimens of the coolside waste to observe the effects of aging on the total stress parameters, $\phi_{u}$, the angle of internal friction, and $c_{u}$, the cohesive strength component. Generally, confining pressures of 138,276 , and 414 $\mathrm{kPa}$ were used for a given series at a selected aging time. since the specimens hydrate and the strength changes with aging time,each specimen of a test series $(138,276$, and $414 \mathrm{kPa})$ at a selected aging period was tested precisely at end of the selected aging time. Variation of the parameters, $\phi_{u}$ and $c_{u}$, with aging time is shown in Figures 13 and 14 . The parameter $\phi_{u}$ ranges from about 29.3 to 32.9 degrees. The strength parameter, $c_{u}$, increases from about $62 \mathrm{kPa}$ (one-day aging time) to $467 \mathrm{kPa}$ (21-day aging time). The increase of $\phi_{u}$ with increasing aging time was not expected and a number of additional tests are scheduled to verify this result.

Permeability - Permeability, or hydraulic conductivity, is the ability of a material to transmit fluid. Hydraulic conductivity depends on unit weight, pore spacing, and degree of saturation of the material. The coefficient of permeability, $k$, is an important parameter used in engineering applications to determine rate and quantity of flow through a material. Permeability tests were performed on specimens remolded to different densities and different aging times. The tests were performed using a back 


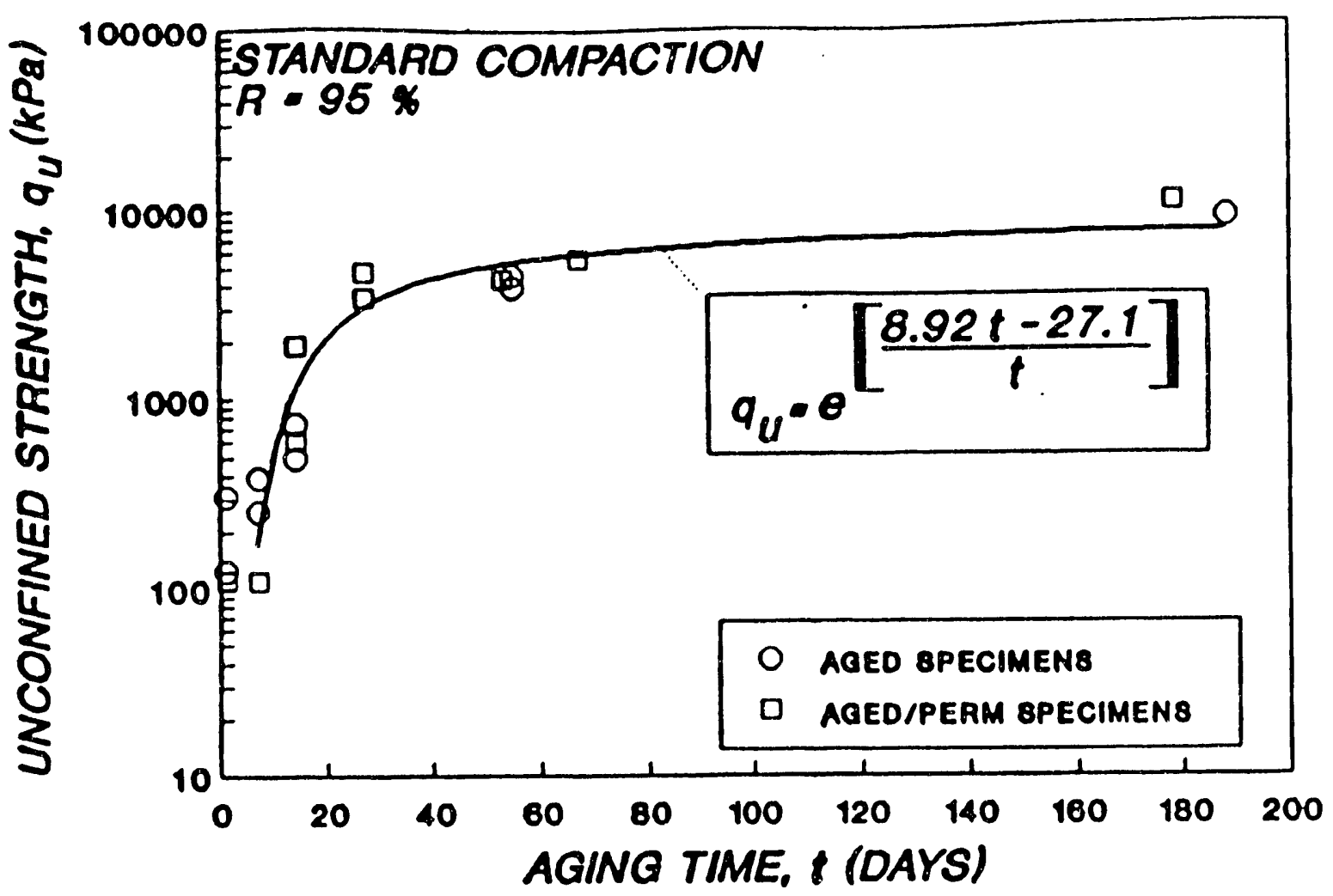

Figure 12 Variation of the unconfined compressive strength of compacted specimens of the Coolside waste and time of aging

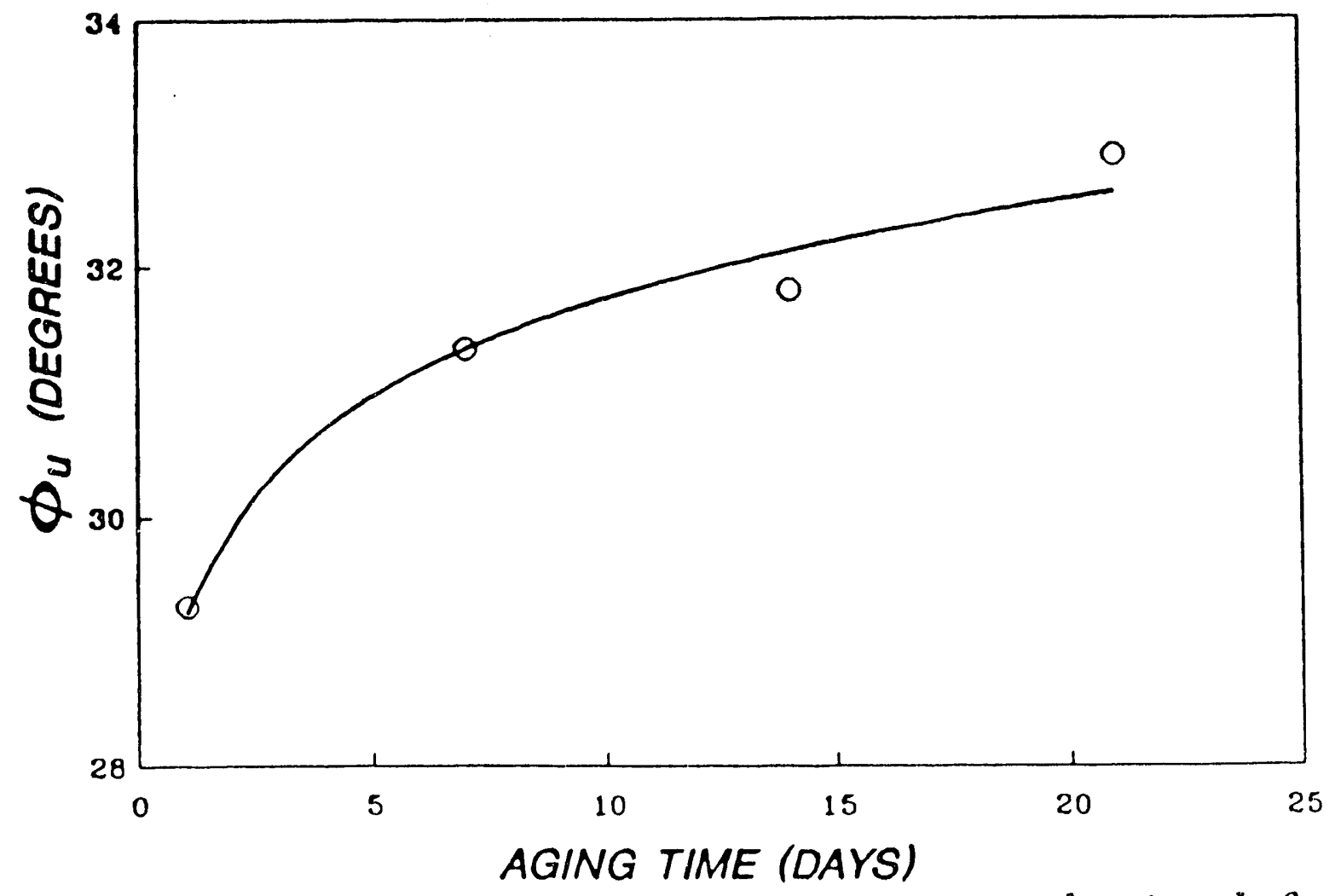

Figure 13 Total stress parameter, $\phi_{u}$, obtained from unconsolidated-undrained triaxial compression tests as a function of time of aging 43 
saturation technique and falling head method in triaxial cells.8 Equations for calculating the coefficient of permeability have been described by Daniel.9 Analysis indicate that aging does not affect the permeability coefficient. However, the coefficient decreases as the void ratio decreases and the dry density increases. The relationship between the permeability coefficient and void ratio (volume of voids divided by the volume of solids) is shown in Figure 15. The coefficient of permeability ranges from about $4 \times 10^{-5} \mathrm{~cm} / \mathrm{sec}$ to $3 \times 10^{-6} \mathrm{~cm} / \mathrm{sec}$. The degree of permeability of the compacted specimens of the coolside waste may be described as low to very low. However, the material in a compacted state is not impermeable since the coefficient of permeability is not smaller than $10^{-7} \mathrm{~cm} / \mathrm{sec}$.

Potential Applications - Based on the results obtained to date from index and physical properties' tests, there are a number of potential engineering applications wise the coolside waste might be used. For example, in sanitary landfill operations, the Coolside waste might serve as a source of material for daily coverage of landfill waste where permeability requirements are not as demanding as those required for topcaps or liner material. Because of the relatively low density of the coolside material after compaction, the coolside waste could be useful in constructing lightweight highway embankments over soft foundations to reduce settlements. Constructing bridge approach embankments with the coolside material could especially be useful to reduce or minimize differential settlements between the ends of the bridge roadway and the approach pavements (the bump at the end of the bridge). The wet density of compacted soils typically range from approximately 16.7 to $23.0 \mathrm{kN} / \mathrm{m}^{3}$. The wet density of the coolside waste at standard compaction and optimum moisture content is about $15 \mathrm{kN} / \mathrm{m}^{3}$,

${ }^{8}$ U.S. Army Corps of Engineers; (1980), "Laboratory Soils Testing," Engineer Manual EM 1110-2-1906.

${ }^{9}$ Daniel, D.E.; (1989), "A Note on Falling Headwater and Rising Tailwater Permeability Tests," Geotechnical Testing Journal GTJODJ, Volume 12, Number 4, December 1989. 


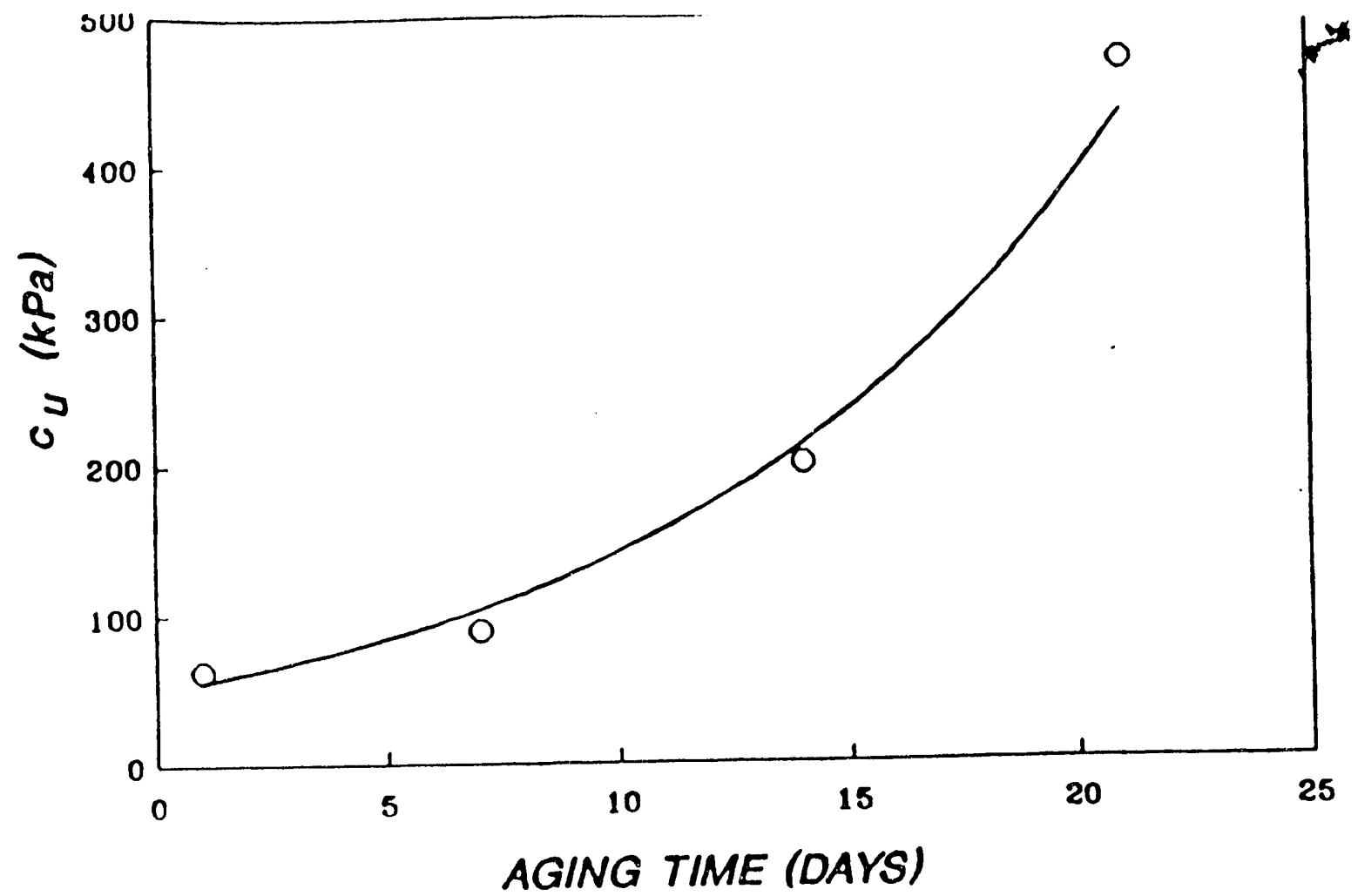

Figure 14 Total stress parameter, $c_{w}$ obtained from unconsolidated-undrained triaxial compression tests as a function of time of aging

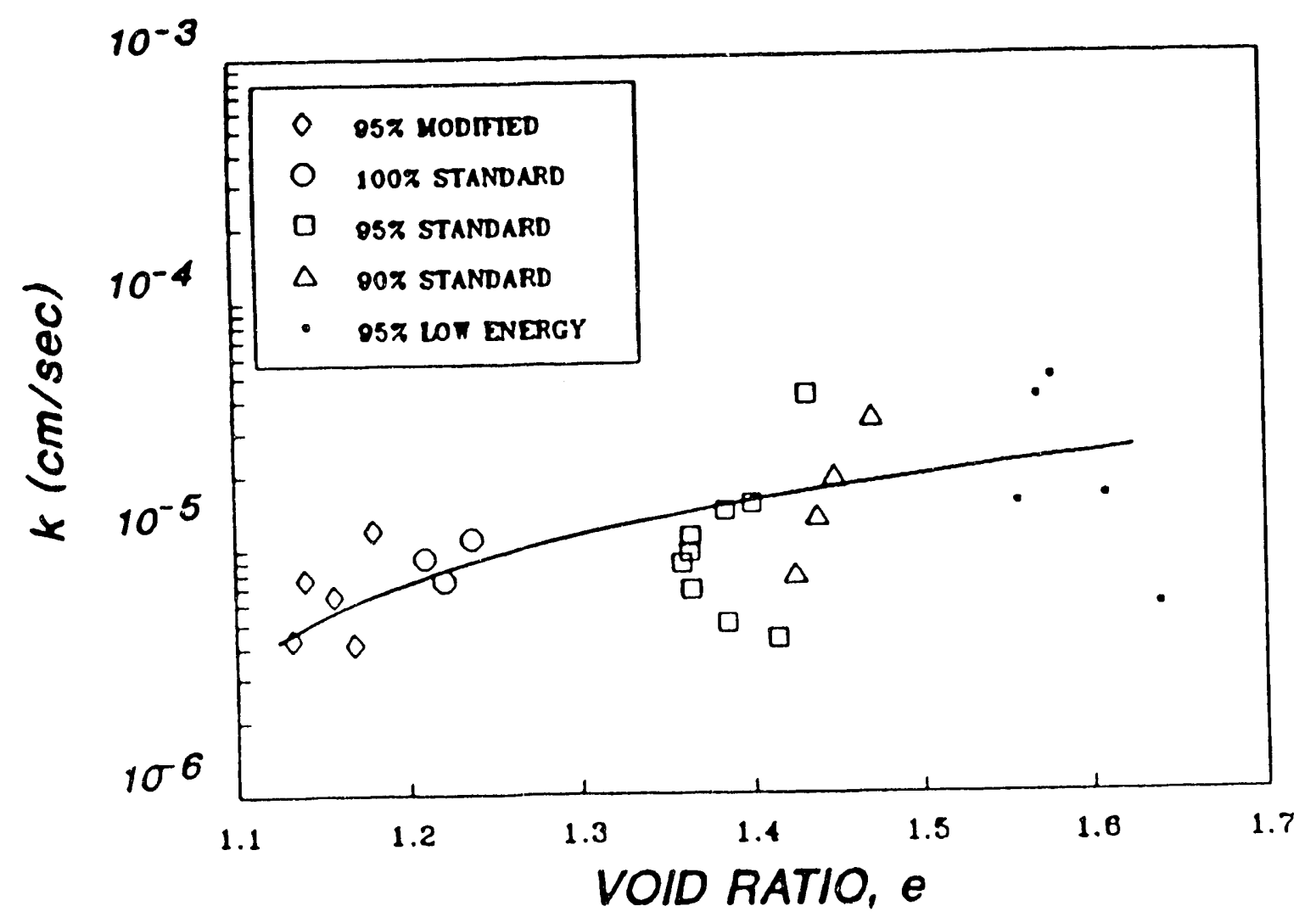

Figure 15. Variation of the coefficient of permeability, $k$, and void ratio, $e$, of compacted specimens of the Coolside waste 
Moreover, as the material hydrates, the shear strength increases with aging. The high values of shear strength of the materials after aging could aid in reducing right-of-way requirements and costs (especially in urban areas where land costs are high) since slopes of embankments built with the coolside waste could be constructed at steeper angles than slopes of embankments constructed with typical soils. Initially, in the construction of steepen slopes it may be necessary to provide some nominal amount of a geosynthetic reinforcing fabric so that the coolside embankment could be constructed to the desired dimensions. As the material ages and gains strength, the steepen slope would attain high stability.

Another potential application consists of using the coolside waste to improve pavement foundations. Because of the high bearing strengths of the material after aging, the material could be used to construct the top portion of pavement subgrades and bases in roadway areas where low-bearing soils are prevalent. Hence, use of the high-strength coolside material instead of lowbearing soils would improve pavement performance and reduce future maintenance costs. Final assessment of the uses of the material in various engineering applications must not be made until the material is subjected to rigorous field trials, additional laboratory tests, and engineering analysis.

\section{TASR 3 - FIELD LEACHING STUDIES}

The four cells of the field lysimeters were cleaned and temporary covers put in place before filling began. A mixing pad ( $8 \mathrm{ft} x$ $15 \mathrm{ft}$ ) was built and completed at the site before loading activities commenced. Water storage capability was added for moistening samples during the filling process. Tl.e water, which will be trucked from Mount sterling, was checked for trace metal concentrations.

All materials, equipment and supplies for filling the field lysimeters. including 30,000 lbs of ottawa sand to serve as the 
base layer in the lysimeters was ordered and transported to the site as needed. Samples of the sand and the soils used in filling was analyzed by the TCLP extraction technique to determine if any impurities are present that may complicate interpretation of the overall results. The results of those extractions is discussed in Task 4 below. of particular concern was the possible presence of adsorbed or occluded soluble species that would leach out during the early stages of the leaching thereby possibly generating significant impurities in the initial leachate samples. To prevent this from occurring samples of the ottawa sand to be used in the bottom of these cells were obtained before hand and run through the leaching procedure and the leachates analyzed for trace metal and anion composition. Among the items obtained to support the filling operation were:

1. Thirty $44 \times 44$ inch pallets for drum transportation.

2. Steel banding ( $1 / 2$ inch) for securing drums to pallets.

3. Rototiller for material mixing.

4. 750 and 325 gallon water tanks for transport to and onside storage.

5. $10^{\prime} \times 10^{\prime}$ frame and canvas for covering lysimeter.

6. Two $30 \times 40 \mathrm{ft}$ tarpaulins for on-site drum storage covers

7. 30,000 lbs of crystal ottawa sand for $1 \mathrm{ft}$ base pad in lysimeters.

\section{TASK 4 - LABORATORY LEACHING STUDIES}

\section{BATCH PROCEDURES}

Liquid extraction of the coolside material using the TCLP, EPTOX, and ASTM-A and B procedures and analysis of the extracts, except for mercury, were performed. The use of these four extraction procedures enabled intra-test comparisons and evaluations with respect to test variables, such as leaching media composition, contact time, and solid:liquid ratio. In these tests, a weighed amount of solid waste material was contacted with a known amount of liquid extractant under specified control condition. After a prescribed time period the liquid extract was separated from the host material and analyzed for extractable waste constituents. 
Analysis Procedures - Four extractions were performed on the Coolside material; two proposed ASTM procedures, i.e., ASTM A and $B$, and two standard EPA extractions, i.e., EPTOX and TCLP were used. The two ASTM procedures operate at a solid to liquid ratio of 1:4, which is more concentrated than both EPA procedures which operate at a 1:20 ratio. ASTM A used distilled water while ASTM B used a sodium acetate-acetic acid buffer, which is comparable to the sodium acetate buffered extraction fluid used in the TCLP (Extraction fluid $* 1$ ). All extractions were performed under controlled conditions as dictated by the various procedures. After addition of the extraction medium to the solid samples they were placed on a Lab-Line orbit Environ-Shaker that provided constant movement of the aqueous phase operating at 70 one-inch strokes per minute without the incorporation of air. (See Extraction Procedures Table 10) The two ASTM methods are described as being a rapid method for obtaining a solution for evaluation of the extractable materials from a waste in order to provide an estimate of the relative environmental hazard associated with a particular waste sample.

Table 10

Extraction Procedures

\begin{tabular}{|c|c|c|c|c|}
\hline Characteristics & TCLP & EPTOX & ASTM-A & A8TM-B \\
\hline Leaching Media & $\begin{array}{l}\text { pH } 2.88 \\
\text { buffer }\end{array}$ & $\begin{array}{l}\text { Dist. } \mathrm{H} 2 \mathrm{O} \\
(\mathrm{pH} 4.8-5 .\end{array}$ & $\begin{array}{l}\text { Dist. } \mathrm{H} 2 \mathrm{O} \\
\text { 2) }\end{array}$ & $\begin{array}{l}\text { pH } 4.5 \\
\text { buffer }\end{array}$ \\
\hline solid:Liquid Ratio & & $1: 20$ & $1: 20$ & $\begin{array}{l}1: 4 \\
1: 4\end{array}$ \\
\hline Test Duration & $18 \mathrm{hrs}$ & $24 \mathrm{hrs}$ & $48 \mathrm{hrs}$ & $48 \mathrm{hrs}$ \\
\hline Particle size & $<1 \mathrm{~cm}$ & $<1 \mathrm{~cm}$ & (As D & isposed) \\
\hline
\end{tabular}

The EPTOX extraction is the procedure formerly used by the EPA in the determining the toxic characteristic of a waste. The EPTOX 
uses a $0.5 \mathrm{~N}$ acetic acid solution to buffer the sample to a $\mathrm{pH}$ of 5 after diluting with water. The amount of acid used can be no more than 4 times the sample weight with the solid to liquid ratio being 1:20. Agitation of the sample was implemented by placing the sample with DI water and buffer solution into a beaker with a stir bar, placed on a stir plate and mixed for 24 hours.

The TCLP like the EPTOX requires a 1:20 solid to liquid ratio and a buffer solution determined by the $\mathrm{pH}$ performed on the solid sample. The extraction medium (extraction fluid \#2) was composed of acetic acid measured at a $\mathrm{pH}$ of 2.88. The amount of extraction fluid was determined as follows:

$20 \times \&$ solids in $\mathrm{spl} \times$ wt of waste

wt extraction fluid =

100

The sample was then placed into a Lars-Lande rotary extractor that rotates at $30 \mathrm{rpm}$ for 18 hours. The sample was filtered through a pressure filter and the extract was then analyzed.

Ion Determination in Leachate - The analytical data presented in this report were obtained by following the specific EPA Methods including: 1) SW-846, Test Methods for Evaluating Solid Waste; 2) EPA Method 1620, Metals by Inductively Coupled Plasma Atomic Emission Spectroscopy; and 3) Method 300.0, The Determination of Inorganic Anions in Water by Ion Chromatography. Conductivity and $\mathrm{pH}$ determinations were made using classical electrometric techniques. An orion microprocessor ion analyzer/901 was used to measure $\mathrm{pH}$ while a YSI model 32 conductance meter measured conductivity.

Major and trace metals were analyzed by using a spectrametrics DCP-AES and a spectrametrics ICP-AES in conjunction with a CETAC U-5000 Ultrasonic Nebulizer. As, Se, and $\mathrm{Hg}$ were analyzed by the 
classic hydride method using a Perkin-Elmer FIAS (Flow Injection Analysis System) long with the Perkin-Elmer 3100 Atomic Absorption unit. Data presented in the tables are expressed as $\mathrm{mg} / \mathrm{l}$ (ppm) unless otherwise noted.

Analysis Results - The leachate data in Table 11 contain the results from the four extraction procedures. As mentioned the primary objective of the study was to determine the potential toxicity of the coolside material using the TCLP and comparing the other extractions to this procedure. Ultimately the coolside material passed the limits set forth by RCRA (Resource Conservation and Recovery Act) in this toxicity characteristic procedure as will be discussed below. The eight EPA metals were all well below the limits.

There were no major surprises resulting from these extraction procedures. The concentrations of the majority of the trace metals were below the instrument's detection limits. A general comparison reveals a pattern showing the ASTM extracts producing higher concentrations of the major and some trace metals. The higher concentrations point to the solid to liquid ratios of the higher concentrations of the major and some trace metals. The higher concentrations point to the solid to liquid ratios of the ASTM procedures as compared to the EPA extracts, (Ratios 1:4 as opposed to 1:20, accordingly.) ASTM-B extract shows a higher concentration than the ASTM-A extract, most likely due to the buffer added to ASTM-B. The TCLP also shows higher yields than the EPTOX because of the lower pH buffer and a more rigorous agitation method. $K$ and se show this pattern easily observed from Figures 16 and 17. There are, however, some anomalies in the data base such as $\mathrm{Mg}$ in which the concentration is much higher in the TCLP than in the ASTM extracts as shown in Figure 18. 
Table 11. Waste Extraction Kethod Leachate Test Results

\begin{tabular}{|c|c|c|c|c|}
\hline Element & TCLP & EPTOX & ASTM-A & ASTM-B \\
\hline A1 & $<.05$ & $<.05$ & $<.05$ & $<.05$ \\
\hline Ag & $<.01$ & $<.01$ & $<.01$ & $<.01$ \\
\hline As & .014 & $<.0005$ & .013 & .017 \\
\hline $\mathbf{B a}$ & .235 & 1.08 & .35 & .37 \\
\hline $\mathbf{B e}$ & $<.0001$ & $<.0001$ & $<.0001$ & $<.0001$ \\
\hline ca & .278 & $.14 \%$ & $.12 \%$ & .208 \\
\hline cd & $<.001$ & $<.001$ & $<.001$ & $<.001$ \\
\hline Co & $<.005$ & $<.005$ & $<.005$ & $<.005$ \\
\hline Cr & .004 & .008 & .020 & .019 \\
\hline $\mathbf{c u}$ & $<.003$ & $<.003$ & $<.003$ & $<.003$ \\
\hline $\mathbf{F e}$ & .192 & $<.005$ & $<.005$ & $<.005$ \\
\hline Hg & $<.0005$ & $<.0005$ & $<.0005$ & $<.0005$ \\
\hline $\mathbf{R}$ & 36.0 & 26.0 & 110.0 & 120.0 \\
\hline Mg & .270 & .023 & .021 & .065 \\
\hline MO & .353 & $<.005$ & $<.005$ & $<.005$ \\
\hline Na & 685.0 & 514.0 & $.11 \%$ & $.12 \%$ \\
\hline $\mathbf{N i}$ & $<.005$ & $<.005$ & $<.005$ & $<.005$ \\
\hline $\mathbf{P}$ & $<.005$ & $<.005$ & $<.005$ & $<.005$ \\
\hline $\mathbf{P b}$ & $<.02$ & $<.02$ & $<.02$ & $<.02$ \\
\hline $8 e$ & .204 & .138 & .434 & .460 \\
\hline 81 & .710 & .070 & .490 & .550 \\
\hline$T i$ & .010 & $<.002$ & $<.002$ & $<.002$ \\
\hline $\boldsymbol{\nabla}$ & .003 & $<.003$ & $<.003$ & $<.003$ \\
\hline $\mathbf{z n}$ & .005 & .005 & .006 & .004 \\
\hline
\end{tabular}


Figure 16

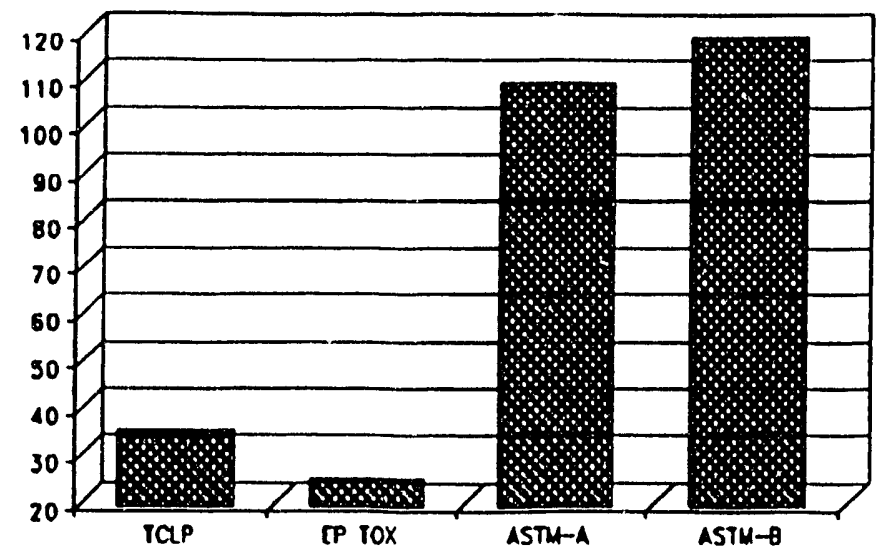

Figure 17

Se

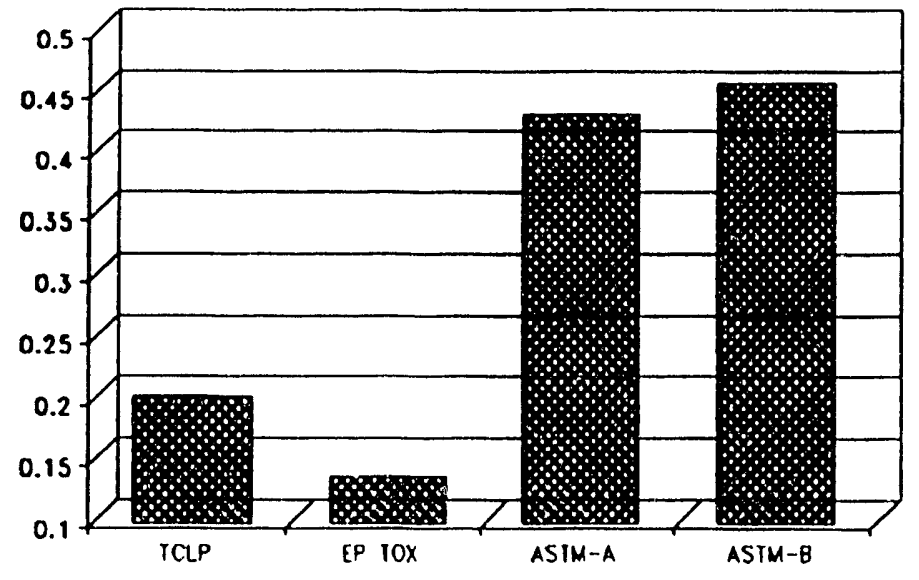


Figure 18

$\mathrm{Mg}$

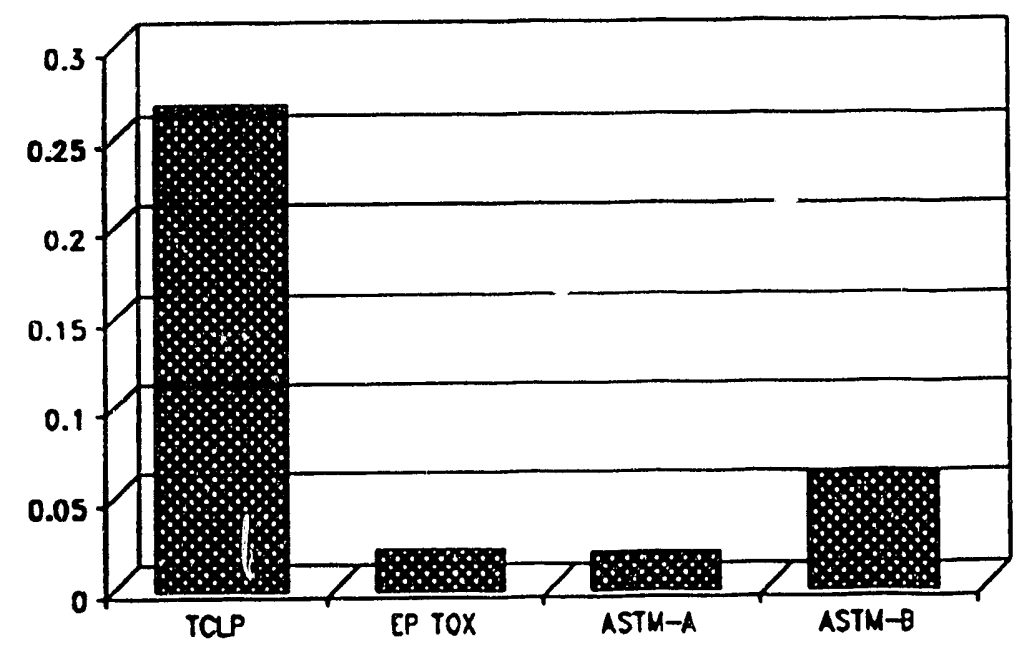




\section{WAGTE CHARACTERIZATION}

Under RCRA there are four characteristics that are used to define non-exempted waste materials that designated hazardous waste. The definitions of these characteristics covered under that legislation are defined in the Code of Federal Regulations Volume 40 .

\section{1) Toxicity Characteristics: Waste materials which} produce leachates in the TCLP having heavy metal concentrations equal to or in excess of the following limits are designated RCRA wastes.

$\begin{array}{ccc}\text { Element } & \text { Limit }(\mathrm{mg} / 1) & \text { Coolside } \\ \mathrm{Ag} & 5.0 & <0.01 \\ \mathrm{As} & 5.0 & 0.014 \\ \mathrm{Ba} & 100.0 & 0.235 \\ \mathrm{Cd} & 1.0 & <0.001 \\ \mathrm{Cr} & 5.0 & 0.004 \\ \mathrm{Hg} & 0.2 & <0.0005 \\ \mathrm{~Pb} & 5.0 & <0.02 \\ \mathrm{Se} & 1.0 & 0.204\end{array}$

2) Ignitability: A material is a RCRA waste if it exhibits a flash point of less than $140^{\circ} \mathrm{F}\left(60^{\circ} \mathrm{C}\right)$.

3) Reactivity: A material is a RCRA waste if it is unstable, reacts violently with water, is sufficiently cyanide or sulfide bearing to produce toxic gas, or is capable of detonation.

4) Corrosivity: A material is a RCRA waste if it exhibits a $\mathrm{pH}$ of less than 2.0 or greater than 12.5 , or corrodes steel at a rate greater than $6.35 \mathrm{~mm}$ per year at $55 \mathrm{C}$.

The heavy metai concentrations in the Coolside material were less than those specified under TCLP. The material is a nonreactive 
inorganic solid and is completely non-combustible such that the Ignitability and Reactivity characteristic does not apply. The material exhibits a pH greater than 12.5 and would therefore be corrosive. However, since it is a solid material the Corrosivity characteristic does not apply. EPA's SW-846 Corrosivity test states that "A solid waste exhibits the characteristic of corrosivity if a representative sample is aqueous and corrodes steel". Since the coolside material is non-aqueous this characteristic does not apply. However, for disposal purposes, the leachate from the field lysimeter will be considered corrosive. To supplement the corrosivity characteristic please see pH table below.

\section{pH Table \\ Method $9045(8 \%-846)^{\circ}$}

Soil pH

13.55
Calcareous soil pH

12.67

* Method 9045 is an electrometric procedure which has been approved for measuring $\mathrm{pH}$ in calcareous and non-calcareous soils.

Non-calcareous soil: 20 grams of sample was placed in a $100 \mathrm{ml}$ beaker along with $20 \mathrm{ml}$ of DI water. The sample was stirred for 30 minutes then allowed to settle for 1 hour. The $\mathrm{pH}$ of the aqueous portion was then measured.

Calcareous soil: 10 grams of sample was placed in a $100 \mathrm{ml}$ beaker along with $20 \mathrm{ml}$ of 3.01 M calcium chloride solution. The sample was stirred for 30 minutes then allowed to settle for 1 hour. The $\mathrm{pH}$ of the aqueous portion was then measured.

\section{COLUMN STUDIES}

In addition to batch extractions, two columns were also investigated in order to predict the leaching characteristics that 
will occur in the field and the lab. Secondly, the columns were prepared to study the migration of water through the column and observe the swelling capacity of the material. Two columns were assembled. Column one was loosely packed while column two was tightly compacted with the use a wooded dowel and human mechanics. Very little difference was observed in the migration rate of water through the columns and channeling was not apparent. Data on the loosely packed column which was taken over a 44 day period are shown in Table 12. The corresponding data on the compacted column taken over the same period are shown in Table 13.

The $\mathrm{pH}$ of the column leachates indicate the coolside waste is strongly alkaline with leachate $\mathrm{pH}$ values of 1.2 .5 suggesting that the leachate from the field lysimeter will require treating before disposal. The major constituents of the leachates were $\mathrm{SO}_{4}, \mathrm{Cl}, \mathrm{Na}$, and $\mathrm{Ca}$. These cations and anions leached rapidly but reached equilibrium in a fairly short time. From Figure 19 it is apparent that these cations and anions level out within approximately 4 weeks.

Pilot plant samples of coolside Materials - Extraction data of the Coolside pellets and ottawa base sand are contained in Table 14 . Metal concentrations from the coolside pellets extraction fluid and the base sand extraction fluid were obtained by ICP-DCP atomic emission spectroscopy while the hydride metals (As, Se, Hg) by FIAS (Flow Injection Analysis system). The initial pH of the pellets measured 11.30 while the sand measured 6.50. High $\mathrm{pH}$ measurements of both materials called for the addition of $3.5 \mathrm{ml}$ of $1 \mathrm{~N} \mathrm{HCl}$ to the slurries and a measurement was again taken. The coolside pellets had a pH of 6.30 resulting in the use of extraction fluid \# 2 while the base sand measured 1.83 resulting in the use of extraction fluid \#1. Final pH from the extract of the pellets measured 7.00 and the sand measured 4.81 . 
Table 12. Loose-Packed Column Leachate Data

\begin{tabular}{|c|c|c|c|c|c|c|c|c|}
\hline Date/ & Inches & pH & Cond & $\mathrm{Ca}$ & $\mathbf{K}$ & Na & Cl & 804 \\
\hline 7 & 6 & 12.45 & 58.80 & 1770 & 715 & 14800 & 15107 & 7857 \\
\hline & 7 & 12.42 & 52.81 & 1280 & 745 & 15500 & 16769 & 8083 \\
\hline 9 & 8 & 12.38 & 39.90 & 870 & 480 & 9300 & 10791 & 5965 \\
\hline 12 & 9 & 12.55 & 29.90 & 870 & 444 & 7700 & 6801 & 4674 \\
\hline 13 & 10 & 12.41 & 29.40 & 850 & 372 & 5250 & 5446 & 4395 \\
\hline 14 & 11 & 12.56 & 24.60 & 820 & 378 & 5000 & 4636 & 4194 \\
\hline 15 & 12 & 12.81 & 23.80 & 812 & 380 & 4750 & 3771 & 4132 \\
\hline 16 & 13 & 12.81 & 23.60 & 761 & 370 & 4300 & 2862 & 4234 \\
\hline 19 & 14 & 12.88 & 22.50 & 564 & 387 & 4100 & 1897 & 4153 \\
\hline 20 & 15 & 12.86 & 20.50 & 600 & 407 & 3550 & 1907 & 4181 \\
\hline 21 & 16 & 12.86 & 17.40 & 620 & 365 & 2800 & 674 & 3032 \\
\hline 22 & 17 & 12.86 & 14.60 & 615 & 285 & 1850 & 382 & 2157 \\
\hline 23 & 18 & 12.83 & 11.90 & 682 & 260 & 1230 & 200 & 1165 \\
\hline 26 & 19 & 12.71 & 10.70 & 374 & 360 & 865 & 121 & 337 \\
\hline 27 & 20 & 12.74 & 10.00 & 459 & 404 & 620 & 91 & 118 \\
\hline 28 & 21 & 12.60 & 10.20 & 484 & 433 & 438 & 81 & 47 \\
\hline 29 & 22 & 12.61 & 9.80 & 487 & 480 & 393 & 72 & 22 \\
\hline 30 & 23 & 12.71 & 9.30 & 470 & 496 & 335 & 74 & 16 \\
\hline 33 & 24 & 12.62 & 9.10 & 402 & 540 & 310 & 56 & 7 \\
\hline 34 & 25 & 12.70 & 8.30 & 441 & 575 & 264 & 50 & 5 \\
\hline 35 & 26 & 12.72 & 8.10 & 483 & 552 & 232 & 43 & 5 \\
\hline 36 & 27 & 12.73 & 8.20 & 514 & 522 & 206 & 34 & 4 \\
\hline 37 & 28 & 12.68 & 7.80 & 504 & 490 & 177 & 30 & 4 \\
\hline 40 & 29 & 12.65 & 7.90 & 492 & 510 & 167 & 30 & 4 \\
\hline 41 & 30 & 12.59 & 7.90 & 448 & 510 & 177 & 28 & 3 \\
\hline 42 & 31 & 12.55 & 7.80 & 420 & 490 & 152 & 25 & 3 \\
\hline 43 & 32 & 12.59 & 7.40 & 410 & 485 & 111 & 24 & 3 \\
\hline 44 & 33 & 12.59 & 7.30 & 500 & 400 & 100 & 24 & 3 \\
\hline
\end{tabular}


Table 13. Compacted Column Leachate Data

\begin{tabular}{|c|c|c|c|c|c|c|c|c|}
\hline Date/ & Inches & $\mathrm{pH}$ & Cond. & $\mathrm{Ca}$ & $\mathbf{K}$ & $\mathrm{Na}$ & $\mathrm{Cl}$ & SO4 \\
\hline 8 & 7 & 12.40 & 63.6 & 1250 & 955 & 18550 & 24396 & 11552 \\
\hline 9 & 8 & $12 \cdot 30$ & 65.4 & 887 & 972 & 18700 & 23778 & 10872 \\
\hline 12 & 9 & 12.46 & 61.0 & 897 & 1050 & 18800 & 19591 & 9613 \\
\hline 13 & 10 & 12.33 & 56.8 & 846 & 902 & 11200 & 18266 & 9871 \\
\hline 14 & 11 & 12.54 & 39.8 & 770 & 680 & 9000 & 9243 & 8257 \\
\hline 15 & 12 & 12.88 & 29.8 & 675 & 485 & 6400 & 4001 & 7047 \\
\hline 16 & 13 & 12.85 & 26.4 & 635 & 362 & 4900 & 1718 & 6498 \\
\hline 19 & 14 & 12.92 & 23.1 & 501 & 394 & 4400 & 788 & 5577 \\
\hline 20 & 15 & 12.91 & 20.8 & 544 & 388 & 3800 & 455 & 4672 \\
\hline 21 & 16 & 12.88 & 16.7 & 540 & 335 & 2800 & 253 & 3141 \\
\hline 22 & 17 & 12.89 & 13.7 & 535 & 275 & 1620 & 150 & 1969 \\
\hline 23 & 18 & 12.72 & 11.2 & 630 & 276 & 999 & 101 & 964 \\
\hline 26 & 19 & 12.70 & 10.1 & 300 & 377 & 709 & 80 & 206 \\
\hline 27 & 20 & 12.73 & 9.9 & 440 & 450 & 500 & 75 & 96 \\
\hline 28 & 21 & 12.58 & 10.2 & 470 & 488 & 420 & 71 & 38 \\
\hline 29 & 22 & 12.62 & 10.0 & 460 & 540 & 390 & 68 & 16 \\
\hline 30 & 23 & 12.60 & 9.8 & 420 & 550 & 330 & 65 & 9 \\
\hline 33 & 24 & 12.63 & 10.1 & 387 & 660 & 350 & 63 & 6 \\
\hline 34 & 25 & 12.75 & 9.1 & 390 & 690 & 328 & 65 & 5 \\
\hline 35 & 26 & 12.77 & 9.1 & 397 & 682 & 295 & 55 & 5 \\
\hline 36 & 27 & 12.74 & 8.9 & 389 & 670 & 263 & 54 & 4 \\
\hline 37 & 28 & 12.70 & 8.6 & 416 & 628 & 231 & 46 & 4 \\
\hline 40 & 29 & 12.70 & 8.8 & 391 & 623 & 218 & 43 & 4 \\
\hline 41 & 30 & 12.63 & 8.7 & 407 & 630 & 207 & 39 & 4 \\
\hline 42 & 31 & 12.60 & 8.5 & 310 & 620 & 110 & 35 & 4 \\
\hline 43 & 32 & 12.59 & 8.4 & 209 & 580 & 75 & 32 & 3 \\
\hline 44 & 33 & 12.56 & 8.2 & 210 & 580 & 71 & 29 & 3 \\
\hline
\end{tabular}


RCRA limits of metal concentrations are listed in Table 15. It can be clearly seen that the coolside pellets were well below the limits as expected. In fact, except for $\mathrm{Ag}$ and $\mathrm{Se}$ these values were all well below drinking water standards.

Laboratory simulation of Field Lysimeters. - The laboratory lysimeter tests on columns packed with series 300 and 1000 Coolside waste are being run in addition to each of the 4 pilot plant run samples provided by consol. In addition a standard Kentucky fly ash sample was loaded into one column. Each 2 inch diameter column packed to a level of 2 feet was suspended on a glass wool mat topped with 1 inch of ottawa sand. Loadings were made at static, proctor and low packing densities. Of the 25 columns, 13 will be run under conditions simulating annual weekly rainfall taken at a near farmers site. The remaining 12 columns will be kept saturated and be leached at a rate of $70 \mathrm{ml} /$ week, which is equivalent to 1 $1 / 3$ inches of rainfall per week, a rate slightly higher than observed in that area. In addition, the effect of an enriched $\mathrm{CO}_{2}$ partial pressure over the column on the column performance and the composition of the leachate will be determined.

Analysis of the leachate will follow protocol established in the program. Total material balances and metal and ion balances around the columns will be developed. 
Table 14. Metals Analysis for TCLP Leachates

\begin{tabular}{|c|c|c|}
\hline Element & Coolside Pellets & Ottawa Base Band \\
\hline AI & $<.05$ & .15 \\
\hline Ag & .09 & $<.01$ \\
\hline As & $<.0005$ & $<.0005$ \\
\hline $\mathbf{B a}$ & 0.071 & $<.001$ \\
\hline Be & .002 & $<.0001$ \\
\hline $\mathbf{C a}$ & $.31 \%$ & .68 \\
\hline Cd & $<.001$ & $<.001$ \\
\hline Co & .027 & $<.005$ \\
\hline Cr & .023 & .006 \\
\hline $\mathrm{cu}$ & $<.003$ & .020 \\
\hline Fe & .08 & .39 \\
\hline Hg & $<.0005$ & $<.0005$ \\
\hline $\mathbf{K}$ & 115.0 & 6.0 \\
\hline Mg & 82.0 & .15 \\
\hline Mo & .281 & $<.005$ \\
\hline Na & 375.0 & $\star \star \star$ \\
\hline $\mathbf{N i}$ & .083 & $<.005$ \\
\hline $\mathbf{P}$ & $<.005$ & $<.005$ \\
\hline $\mathbf{P b}$ & $<.02$ & $<.02$ \\
\hline Se & .061 & $<.0005$ \\
\hline $\mathbf{6 i}$ & 4.40 & .26 \\
\hline $\mathbf{T i}$ & .007 & .005 \\
\hline $\mathbf{v}$ & .013 & $<.003$ \\
\hline $\mathbf{z n}$ & .027 & .009 \\
\hline
\end{tabular}


Table 15. RCRA Metal Concentrations in Coolside Pellets

$\begin{array}{ccc}\text { Element } & \text { Limit }(\mathrm{mg} / \mathrm{l}) & \text { Coolside Pellets } \\ \text { Ag } & 5.0 & 0.09 \\ \text { As } & 5.0 & <0.0005 \\ \text { Ba } & 100.0 & 0.071 \\ \text { Cd } & 1.0 & <0.001 \\ \text { Cr } & 5.0 & 0.023 \\ \text { Hg } & 0.2 & <0.0005 \\ \text { Pb } & 5.0 & <0.02 \\ \text { 8e } & 1.0 & 0.061\end{array}$



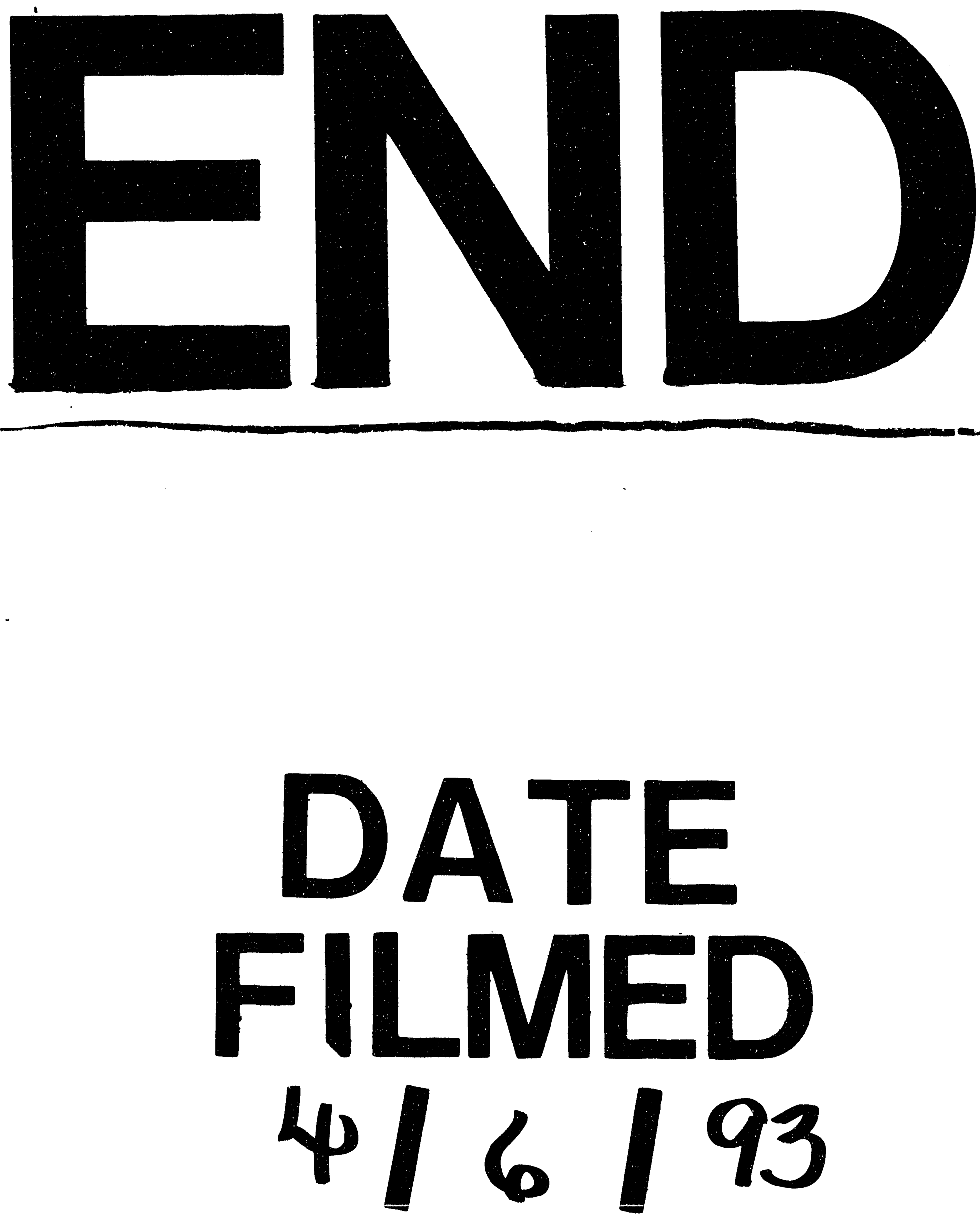

i 
